\title{
O Ensino da Mecânica Quântica no nível médio por meio da abstração científica presente na interface Física-Literatura
}

\author{
Luís Gomes de Lima ${ }^{1}$ \\ Programa de Pós-Graduação da Faculdade de Educação \\ Universidade de São Paulo \\ São Paulo - SP \\ Elio Carlos Ricardol \\ Faculdade de Educação - Universidade de São Paulo \\ Instituto de Estudios de la Ciencia y la Tecnología \\ Universidad de Salamanca - Espanha
}

\section{Resumo}

O presente artigo tem por objetivo investigar o ensino da Mecânica Quântica no Ensino Médio por meio da abstração científica criada na interface física e literatura e é fruto da pesquisa de dissertação presente em Lima (2014). A relação entre física e literatura é defendida com o propósito de ser utilizada como ferramenta ao ensino e aprendizagem da física, especialmente por propiciar o desenvolvimento da abstração científica. A formação de conceitos científicos e a importância da palavra são analisadas em Vygotsky, na formação dos pseudoconceitos e desenvolvimento da abstração, juntamente com o aporte das representações semióticas de Raymond Duval. O desenvolvimento dos conceitos sobre Mecânica Quântica ocorreu por meio de duas leituras. A primeira tratou do capítulo XVIII da Era dos Extremos de Hobsbawm, objetivando a inserção filosófica, histórica, política e social sobre o surgimento da Física Quântica. A segunda ocorreu por meio da leitura dos três capítulos iniciais de Alice no País do Quantum de Gilmore, visando os conceitos físicos de Mecânica Quântica. Os dados colhidos dos alunos após a leitura e a análise destes apontam a interface física-literatura como uma

\footnotetext{
${ }^{+}$The teaching the Quantum Mechanics in high school through scientific abstraction present in Physics Literature interface

* Recebido: dezembro de 2017. Aceito: dezembro de 2018.

${ }^{1}$ E-mails: luis.gomes.lima@usp.br; elioricardo@usp.br
} 
alternativa didática promissora para o ensino da Mecânica Quântica, em particular, e para o ensino da física, em geral.

Palavras-chave: Mecânica Quântica; Física e Literatura; Abstração; Conceitos Físicos.

\begin{abstract}
This article proposes to investigate the teaching of Quantum Mechanics in high school through scientific abstraction created in physics and literature interface and is the result of the dissertation research present in Lima (2014). The relationship between physics and literature is held for the purpose of being used as a tool for teaching and learning physics, especially for providing the development of scientific abstraction. The formation of scientific concepts and the importance of the word are analyzed in Vygotsky, in the formation of pseudoconcepts and development of abstraction, together with the contribution of semiotic representations of Raymond Duval. The development of Quantum Mechanics concepts occurred through two readings. The first reading took place about the eighteenth chapter of the Age of Extremes by Hobsbawm, aiming to insert philosophical, historical, political and social information on the advent of Quantum Physics. The second reading took place through reading the first three chapters of Alice in Quantum Country by Gilmore, targeting the physical concepts of Quantum Mechanics. The data collected from the students after the reading and the analysis of these point the physical-literature interface as a promising didactic alternative for the teaching of Quantum Mechanics in particular and for the teaching of physics in general.
\end{abstract}

Keywords: Quantum Mechanics; Physics and Literature; Abstraction; Physical Concepts.

\title{
I. Introdução
}

Em seu livro Diálogo sobre os dois máximos sistemas do mundo ptolomaico e copernicano, na tradução de Mariconda (2004), Galileu Galilei retrata o emprego da argumentação e da dialética, como meio para os quais se busca fazer entender determinado objeto cognoscível, no caso em questão, o movimento da Terra, não somente por meio do convencimento pela argumentação, mas pela imposição de fazer o outro pensar. Tal estratégia consistiu-se 
no diálogo usado por Galileu, baseado na contraposição e contradição das ideias aristotélicoptolomaicas, levando a outras ideias, no caso, ideias copernicanas do movimento da Terra.

Por que diante de diversos métodos disponíveis, Galileu decidiu utilizar justamente a literatura e a dialética para escrever e divulgar sua obra?

Decerto, o Diálogo é uma obra de convencimento, pois Galileu procurava, entre outros objetivos, convencer os matemáticos da época de que o sistema heliocêntrico de Copérnico era mais plausível que o sistema geocêntrico ptolomaico defendido por Aristóteles e seus seguidores. Diante de tarefa tão complexa e perigosa para época, Galileu decide utilizar-se do poder da argumentação, da escrita e da literatura, optando por uma linha dialética entre três personagens. Um representando o conhecimento aristotélico e ptolomaico da imobilidade da Terra, de nome Simplício; outro de nome Sagredo, representando alguém do povo e indiferente à disputa, que acolhe ambas as argumentações e que, ao longo da obra, vê-se inclinado às ideias pregadas pelo terceiro personagem, de nome Salviati, que representa o próprio Galileu em defesa do modelo copernicano de mobilidade da Terra (MARICONDA, 2004).

É importante salientar o Diálogo de Galileu para demonstrar que a leitura, assim como a literatura, pois esta é decorrente daquela, podem ser utilizadas para se compreender conceitos físicos mais complexos. No caso do Diálogo, Galileu, por meio da literatura utilizada, busca apresentar o modelo copernicano a seus contemporâneos, o que para a época era um conceito inovador, provocativo e complexo, o que torna Galileu um didata da física.

Podemos estabelecer, inclusive, uma relação entre a importância do diálogo acima para um processo de ensino e aprendizagem de física, como exposto em Freire (1975), onde o autor ao tratar da dialogicidade, da educação dialógica e do diálogo, nos explica que a relação horizontal entre professor e aluno surge do diálogo, onde a confiança mútua é natural e se estabelece nessa horizontalidade de ensino, sem a imposição de uma educação verticalizada, onde o aluno seja considerado apenas um receptáculo de informações impostas (FREIRE, 1975). Levando em consideração esses aspectos, um ensino de física que seja articulado com a literatura pode vir a promover um ensino de física horizontal.

Uma inserção no ensino de física, nesse contexto, pode promover uma compreensão melhor da disciplina, evitando que se confunda física com matemática, ou que os alunos sejam levados a pensar que a física é uma matemática mais requintada. Essa confusão pode ser verificada em Ricardo e Freire (2007), ao pesquisarem a concepção da física por alunos de Ensino Médio (EM), esclarecem que, para eles, não há basicamente distinção entre física e matemática, muitos confundem as duas disciplinas quando questionados sobre suas diferenças. Essa concepção é ilustrada na resposta de um aluno do $3^{\circ} \mathrm{EM}$ : "Nenhuma, porque tudo acaba em cálculo" (RICARDO; FREIRE, 2007, p. 255). Na pesquisa, os autores alertam para a importância da compreensão do papel da matemática na construção do pensamento físico, uma vez que a diferença entre matemática e física não seja clara, inclusive para os professores. 
Tal desarticulação pode justificar o fato dos alunos não gostarem de física, de acordo com Custódio e Modesto Junior (2009) em um trabalho a respeito das representações sociais de alunos de EM sobre física, constatou-se a palavra ódio como evocação de maior frequência da carga emocional dos estudantes sobre a disciplina. Ao que parece os alunos têm expectativas positivas sobre a disciplina em seu primeiro contato, mas à medida que vão se deparando com uma física exclusivamente algebrizada, aumenta-se a recusa e o ódio pela mesma. Esse sentimento parece ser mais latente nos alunos de $3^{\circ} \mathrm{EM}$, que sentem um repúdio maior à física, do que os do $1^{\circ} \mathrm{EM}$, pois foram os anos estudando essa física desarticulada que, justamente, criou a aversão à disciplina (D’AGOSTIN et al., 2006). Essa constatação denota que os alunos têm curiosidades, das mais diversas sobre as ciências em geral, e em especial sobre a física. Esses anseios poderiam facilmente ser trabalhados por meio de uma articulação entre física, literatura e ficção científica, mas esses alunos acabam sendo podados em suas expectativas, pois logo se veem obrigados à realização de repetições maçantes de exercícios descontextualizados de sentidos. Há necessidade de uma mudança metodológica no ensino de física, que promova uma forma de aprendizado mais cativante e prazerosa. Nesse contexto, Nory e Zanetic (2005), propõem um ensino de física atraente aos alunos e criticam o ensino corrente de física nas salas de aula:

\begin{abstract}
O ensino de Física dominante em nossas escolas ainda é algo totalmente distante de todas as propostas inovadoras produzidas pela área de pesquisa em ensino de física, bem como das recomendações que constam dos PCN, e totalmente desacoplado da realidade. O que é que o aluno encontra duas ou três vezes por semana na sala de aula de Física tradicional? Sempre a mesma coisa: $F=m a, Q=m c \Delta T, F=$ q.v.B $\operatorname{sen} \theta$, que sofre uma leve variação no ensino superior, ficando $F=q v \times B . \dot{E}$ este o tipo de ensino que promove o alcance dos objetivos dos PCN? Temos certeza que não. Não queremos aqui, porém, pregar que a parte matemática dos cursos de Física deva ser abolida. Quero dizer apenas que deve ser complementada (NORY; ZANETIC, 2005).
\end{abstract}

Uma das causas dessa desarticulação pode estar relacionada com a falta de abordagens histórico-filosóficas no ensino de física, bem como pela ausência de inserção de leituras gerais, textos históricos e literaturas específicas. Uma possibilidade que possa dissolver tal confusão é possível mediante a convergência entre física e literatura, que pode ocorrer por meio da história da física, onde há a influências de grandes escritores, desde o início da física clássica no século XVI, e grandes cientistas como Galileu, Kepler, Newton e Einstein (ZANETIC, 1996). Essa pouca utilização da história e filosofia da física como objeto didático que esteja presente, por exemplo, nos livros didáticos, ocorre pelo fato de que não há, ainda, uma forma estabelecida para sua aplicação, conforme ressaltam Guerra e Menezes (2009) ao afirmarem que: "apesar da clara defesa da importância da História e Filosofia da Ciência, os caminhos para trabalhá-la estão ainda sendo construídos" (GUERRA; MENEZES, 2009, p. 3). De acordo, com as autoras a aproximação entre física e literatura pode se constituir em um 
caminho possível para que tenhamos um ensino de física que aborde e contextualize, tanto a história quanto a filosofia da ciência.

Além dessas observações, algumas perguntas podem ser realizadas, a fim de melhor compreendermos como se poderia abordar o ensino de física mediado pela literatura, pela história e pela filosofia. Ou seja, que tipos de história, de filosofia e de literatura podem ser contempladas no ensino de física?

Sobre esses questionamentos, Zanetic (2006b) nos oferece algumas respostas:

Que história da física utilizaria? Opto por uma história que contemple tanto a evolução conceitual e metodológica da física quanto sua relação com outras áreas do conhecimento e com a sociedade de uma maneira geral, enfim a física inserida no processo histórico. Que filosofia da ciência? Sugiro a filosofia da ciência contemporânea, principalmente a que é baseada fortemente na história, que apresenta elementos de análise que enriquecem nossa visão da ciência como instrumento de "diálogo com a natureza". Minha opção fica restrita às epistemologias de Gaston Bachelard, Thomas Kuhn e Paul Feyerabend. Se a filosofia voltasse como disciplina no ensino médio, ficaria ainda mais fácil discutir com os alunos a ruptura epistemológica, a revolução científica, os paradigmas, a proliferação de teorias, a verdade, o método, etc. Que literatura utilizar em aulas de ciência? Brevemente, diria que tenho em mente não apenas os grandes escritores da literatura universal que em suas obras utilizam conceitos e métodos das ciências, e da física em particular, os escritores com veia científica, como também várias obras escritas por cientistas com forte sabor literário, os cientistas com veia literária (ZANETIC, 2006b, p. 43).

Dessas proposições, consideramos que a aproximação entre física e literatura pode ser estabelecida e utilizada didaticamente por meio de uma interface, sendo mediada pelos textos escritos, tanto por cientistas quanto por não cientistas. Sobre esses escritores, Zanetic (2006b), ao denominá-los como escritores com veia científica e cientistas com veia literária, oferece-nos alguns exemplos, a saber: Galileu, H. G. Wells, Einstein, Infeld, Landau, Bohr, Feynman, Edgar Alan Poe, Júlio Verne, Sir Arthur Conan Doyle, Fred Hoyle, Karel Capek, Ray Bradbury, Arthur Clarke, Dante Alighieri e tantos outros. Nessa linha de utilização e articulação entre física e literatura, vale mencionar também Johannes Kepler e seu livro Somnium, publicado em 1634, onde se descreve a viagem do homem à Lua, sendo considerado o primeiro livro de ficção científica da história (CHRISTIANSON, 1976), ou Camões e sua obra Os Lusíadas, onde a visão geocêntrica de mundo está presente em vários versos, além das ficções de Asimov, entre outros, cujas obras podem ser utilizadas em contextos de aproximação com aspectos e elementos diversos que contenham conceitos da física.

Dentro dessas considerações, vale perguntar quão enriquecedor não seria aprender cinemática, só para citar um exemplo, preliminarmente, discutindo os textos históricos de Galileu, como se pode ver em Lima (2012), onde o autor, para além da função horária das posições, utiliza alguns gedankenexperiments presentes no Diálogo de Galileu Galilei para apresentar o conceito de Movimento Retilíneo Uniforme (MRU) aos seus alunos. Aquém des- 
tas exíguas e isoladas práticas, o que se percebe, tanto nos livros didáticos quanto nas práticas de sala de aula, em sua maioria, são conceitos prontos, seguidos de inúmeros exercícios de fixação, desconectados ou desligados de um sentido mais amplo, gerando um verdadeiro desserviço ao ensino de física, o que pode estar relacionado com falta de políticas públicas voltadas ao ensino de ciências.

Neste sentido, Krasilchik (2000), em uma revisão histórica das propostas de reforma do ensino de ciências, lembra que as políticas públicas brasileiras não levaram em conta a aquisição de conhecimentos científicos pela população de forma a que compreendam e reconheçam a ciência como empreendimento social, sendo que os alunos não articulam os saberes ensinados nas salas de aula com os problemas sociais contemporâneos e que os livros continuam sendo o único aporte para transmissão dos conteúdos científicos aos alunos (KRASILCHIK, 2000). Inclusive, segundo Rezende, Ostermann e Ferraz (2009), estudos sobre políticas públicas são escassos no que se refere ao ensino de física. O estado da arte levantado pelas autoras, no período de 2000 a 2007, encontrou apenas 3 publicações a esse respeito, o que mostra a escassez de pesquisas neste aspecto.

Alternativamente ao tipo de ensino criticado até aqui, acreditamos que a articulação entre física e literatura possa contribuir como estratégia promotora de sentidos aos estudantes. Nesse intento, apresentamos, a seguir, as contribuições e justificativas que um ensino de física articulado com a literatura, apoiado nas discussões precedentes, pode oferecer.

\section{I.1 Física e Literatura}

Quais seriam os elementos pertencentes, tanto à física quanto à literatura, que permitiriam um ensino articulado entre duas disciplinas, aparentemente, tão distintas uma da outra?

Uma possível resposta a essa indagação pode encontrar respaldo na revisão bibliográfica sobre física e literatura de Lima e Ricardo (2015), a qual é dividida em três eixos: 1) a leitura no ensino de ciências/física; 2) o papel da divulgação científica no ensino de ciências/física e; 3 ) a analogia e a metáfora no ensino de ciências/física. Além da revisão bibliográfica, os autores apresentam, as contribuições da relação entre física e literatura no ensino e aprendizagem da física.

Conforme Lima e Ricardo (2015) um possível entendimento sobre a interface física e literatura, como aporte ao ensino, ocorre pela utilização de textos escritos que contenham conceitos científicos, os quais ao serem didatizados e mediados pelo professor, possam se transformar em conceitos físicos. É importante ressaltar que entendemos aqui todos tipos de textos escritos nesse sentido, ou seja, textos literários, históricos, filosóficos, sociais, de ficção/divulgação científica, que contenham conceitos físicos, como representantes daquilo que consideramos pela interface física e literatura. Tal definição nos possibilita entender e utilizar essa relação como um recurso que fornece aos estudantes uma compreensão mais abrangente sobre os conceitos físicos, completando e dando significado às descrições matemáticas dos fenômenos físicos, os quais são tão presentes na maioria dos livros didáticos, ou apostilas, e 
estudados em salas de EM. Pode-se, ainda, fornecer uma formação cultural mais ampla e um acesso ao conhecimento científico compreensível e melhor aceito pelos alunos, onde possam aparecer a filosofia e a história da física, suas relações com a sociedade e com a cultura, garantindo uma melhor compreensão da física enquanto atividade humana, minimizando a falta de compreensão e reconhecimento, como foi criticado acima por Krasilchik (2000).

A relação entre física e literatura também é ressaltada por Mecke (2004), ao afirmar que:

A literatura e a física habitam o mesmo ambiente cultural. Não só a física influencia a literatura como vice-versa. Não no sentido de uma causalidade direta, mas sim no de um quadro interpretativo comum, de uma língua comum, de imagens e metáforas comuns. Porque a física vive de metáforas poderosas [...]. Na rotina do nosso quotidiano de físicos esquecemo-nos frequentemente de que são as metáforas, e não as fórmulas, que constituem a espinha dorsal do pensamento (MECKE, 2004, p. 04$11)$.

A importância das metáforas como visto acima, também é ressaltada por Kinouchi et al. (2012), por possibilitar a transposição entre um conhecimento concreto e um conhecimento abstrato, enquanto sua utilização no sentido cognitivo, ao invés do sentido linguístico, encontra respaldos na teoria de Lakoff e Johnson (1980). Os autores ressaltam três tipos de metáforas: estruturais, orientacionais e ontológicas, onde a essência da metáfora é "compreender e experimentar um tipo de coisa em termos de outra", um mapeamento entre um domínio fonte concreto e um domínio alvo abstrato (LAKOFF; JOHNSON, 1980; LAKOFF; NÚÑEZ, 2000). Assim, podemos relacionar a leitura de um texto literário como um domínio fonte concreto, enquanto esperamos que, dessa leitura, surjam elementos que levem a um domínio alvo abstrato, ou seja, um conceito físico.

Além dessa relação apresentada, a interface física e literatura possui relação com a imaginação, pois tanto o escritor quanto o físico necessitam de imaginação na elaboração de seus escritos. O papel dessa relação pode ser encontrado nos estudos de Carvalho e Zanetic (2004; 2005); Gurgel e Pietrocola (2011a; 2011b); Watanabe e Gurgel (2011) e Paula e Borgens (2008). Esses estudos apontam que a imaginação pode ser considerada como a ponte que conecta uma aprendizagem não conceitual em conceitual, como um conhecimento não científico em científico, ou, ainda, entre a formação de um pseudoconceito ${ }^{2}$ e um conceito científico. Essa ponte pode se constituir em boa estratégia de ensino, pois, ao ler o estudante abstrai, cria e imagina os eventos descritos na sua leitura e, quando essa leitura apresenta conceitos específicos de física, através de sua interpretação, são criados pseudoconceitos, os quais, tratados didaticamente, podem se converter nos conceitos físicos pretendidos.

\footnotetext{
2 Em seus estudos sobre a formação de conceitos, Vygotsky (1994; 2008) define o pseudoconceito como uma espécie de pensamento por complexos mais evoluído, sendo uma das etapas finais, atrás, somente, dos conceitos potenciais e desenvolvimento da abstração, para construção de um conceito. O pseudoconceito é dual por natureza, servindo de ponte entre um pensamento por complexos e um pensamento conceitual.
} 
Como já discutido acima, a literatura também é representativa da arte. A física também possui aspectos, não só ligados à imaginação, mas, também, associados à arte, como defendido por Zanetic (2006a). Ao estabelecer uma ponte entre essas duas culturas, o autor promove uma aproximação da física com diversas representações culturais, como a música, a história, a filosofia, a literatura, a divulgação científica, o teatro e as artes plásticas. Ao que parece, a primeira tentativa de se aproximar a cultura científica e a cultura humanística foi elaborada pelo físico e romancista inglês Charles Percy Snow, que criou e cunhou a expressão "duas culturas" para retratar as diversidades entre cientistas e não cientistas. Conforme Snow (1995), os humanistas não conhecem conceitos básicos da ciência e os cientistas não tomam conhecimento das dimensões humanas que a ciência carrega. De acordo com o autor: "quando esses dois sentidos se desenvolvem separados, nenhuma sociedade é capaz de pensar com sabedoria" (SNOW, 1995, p.72).

A denúncia da dicotomia existente entre as duas culturas, a científica e a humanística, não é exclusividade da obra de Snow (1995). Segundo o levantamento, já citado, realizado por Rezende, Ostermann e Ferraz (2009), as pesquisas em ensino de física se resumem, basicamente, aos aspectos cognitivos do ensino-aprendizagem, apoiados em apenas três eixos: desenvolvimento de experimentos para laboratórios didáticos; propostas de metodologias e estratégias de ensino e; recursos didáticos, sendo que a temática classificada pelas autoras como arte, cultura e educação científica resultou em 0 (zero) pesquisas realizadas no período verificado. $\mathrm{O}$ levantamento realizado pelas autoras leva à necessidade de pesquisas teóricas no ensino de física nacional, além da necessidade de se valorar pesquisas que busquem outros olhares ao processo de ensino e aprendizagem de física. Há, ainda, uma dicotomia entre o baixo número de publicações sobre a temática arte, cultura e educação científica nos periódicos nacionais em relação aos internacionais, bem como nas pesquisas de mestrado e doutorado, o que implica que esses trabalhos não estão sendo publicados em forma de artigos nas principais revistas de ensino de ciências (NASCIMENTO; REZENDE JUNIOR, 2010). Essa aridez de publicações sobre o tema merece atenção, o que leva a indagação de, ao menos, duas hipóteses: ou os pesquisadores de mestrado e doutorado não estão enviando seus trabalhos aos periódicos especializados em ensino de física, ou estes não estão aceitando, ou reconhecendo, a importância desta temática nos trabalhos enviados e, consequentemente, recusando as publicações. Ao verificar as principais revistas em ensino de física, constata-se, realmente, um baixíssimo índice de publicações de artigos a respeito da física e literatura, ou sobre aspectos da física em contextos culturais mais amplos, bem como uma investigação mais profunda sobre essa relação.

Embora a temática acima não apareça com maior incidência, podemos elencar algumas vertentes que se aproximem de um eixo de ensino de física cultural mais amplo, como os estudos relativos ao papel da leitura e divulgação científica no ensino de física, como os apresentados por Lima e Ricardo (2015). Em geral, estes estudos vêm apontando para uma aproximação, ressaltam haver relações e indicam para a existência de uma melhor compreensão 
conceitual pelos alunos que leram textos científicos, apresentando, inclusive, melhores resultados, quando comparados com alunos que seguiram um ensino sem leitura alguma (NIGRO; TRIVELATO, 2010). Apontam também para o aumento da curiosidade e do prazer, ao se trabalhar esses conceitos pelo viés da leitura e não pelo formalismo matemático tradicional, desempenhando um papel desencadeador de motivação no leitor, pois sua linguagem é mais acessível, possibilitando um gosto maior por parte dos alunos no estudo da física (MONTEIRO I; GASPAR; MONTEIRO A, 2005).

Nesse propósito, ressaltamos a importância dos estudos relativos ao papel da leitura e da palavra como representação de conceitos científicos, o qual pode ser explorado como aporte à interpretação de conceitos, como apontam os trabalhos de Almeida, Silva e Machado (2001), Andrade e Martins (2006), Barbosa-Lima e Carvalho (2003), Francisco Junior (2009), Nascimento e Barbosa-Lima (2006), Nigro e Trivelatto (2010), Paula e Lima (2010), Padilha e Carvalho (2011), entre outros, como a publicação lançada no Journal of Research in Science Teaching (1994), em número especial, chamado de "The Reading - Science Learning - Writing Connection", cujos artigos, somando onze ao total, tratam das relações entre ensino da ciência e leitura e produção da escrita. A importância da leitura para o aprendizado da física, também encontra respaldos na divulgação científica, conforme Strack, Loguércio e Del Pino (2009), a divulgação científica, por possuir uma linguagem mais simples, propicia uma motivação geradora pelas leituras e, maior interesse por parte dos alunos nos estudos da física.

Ressaltamos que existem estudos que indicam algumas limitações quanto ao uso da leitura, os quais apontam para um possível reforço de concepções alternativas (VIENNOT, 1977), ou erros conceituais presentes em alguns tipos de textos, conforme se pode verificar em Souza e Souza (2005). Alguns outros baseiam suas críticas no uso das analogias e metáforas, como em Francisco Junior (2010). Entretanto, vale ressaltar que não há, por parte das críticas, preocupação em se investigar e valorizar a mediação do professor no uso de recursos textuais no ensino de física. Entendemos que a leitura em si não favorece o aprendizado de conceitos físicos, mas se for mediada pode favorecer, o que mostra a importância de inserção de leituras, também na formação dos professores de física, fomentando a construção de um corpo teórico a ser corretamente utilizado, como se verifica nos trabalhos de Chaves, Mezzomo e Terrazan (2001) e Machi e Leite (2010). É importante lembrar que a prática de leituras não é usual, nem está estabelecida nos conteúdos, sejam de Física Clássica sejam de Física Moderna e Contemporânea (FMC), tanto no EM quanto no Ensino Superior (ES). Entendemos, nesse contexto, que a interface física-literatura pode ser uma ferramenta útil. Se utilizada como ferramenta didática pode contribuir como formadora de sentidos dos conceitos físicos para os alunos.

É nesse contexto que um ensino focado nos aspectos histórico-filosóficos da física contribuiria, também, para aumentar o hábito e o gosto pela leitura por parte dos estudantes, bem como aumentaria suas habilidades de interpretação e análise textuais, além de promover uma visão da ciência como entidade cultural. Esse conjunto de benefícios contribui para cons- 
trução de importantes elementos constituintes na formação dos estudantes de EM. A esse respeito, os Parâmetros Curriculares Nacionais (PCN) para o EM nos lembram que:

\begin{abstract}
A Física percebida enquanto construção histórica, como atividade social humana, emerge da cultura e leva à compreensão de que modelos explicativos não são únicos nem finais, tendo se sucedido ao longo dos tempos, como o modelo geocêntrico, substituído pelo heliocêntrico, a teoria do calórico pelo conceito de calor como energia, ou a sucessão dos vários modelos explicativos para a luz. O surgimento de teorias físicas mantém uma relação complexa com o contexto social em que ocorreram. Perceber essas dimensões históricas e sociais corresponde também ao reconhecimento da presença de elementos da Física em obras literárias, peças de teatro ou obras de arte. Essa percepção do saber físico como construção humana constitui-se condição necessária, mesmo que não suficiente, para que se promova a consciência de uma responsabilidade social e ética (BRASIL, 1998, p. 27-28, grifo nosso).
\end{abstract}

A crítica lançada pelos PCN há mais de 20 anos ainda é atual. A gravidade dessa desarticulação entre conceitos, leis e fórmulas, gera entre outros, um repúdio pelo estudo da física, pela maioria dos estudantes de EM. Não é de se espantar que a grande maioria dos nossos alunos ao serem questionados sobre qual disciplina mais detestam, a física, esteja entre as primeiras colocadas. Constata-se, também, que apesar das críticas e recomendações propostas pelos PCN, além de pesquisas sobre ensino de física, efetivamente, pouca coisa tem mudado na realidade do ensino de física nas salas de aula de EM. A Sociedade Brasileira de Física (SBF), por exemplo, ao realizar uma entrevista com Gonçalves Júnior e Barroso (2014) sobre seu artigo, obtém, a respeito do baixo rendimento dos alunos no Exame Nacional do Ensino Médio (ENEM), o seguinte depoimento ${ }^{3}$ : "Em outras palavras, trabalhar com "contas" amplia nosso conhecimento sobre os conceitos e vice-versa. É absolutamente necessário que o aluno faça conexões mentais, resolva problemas, etc" (SBF, 2014, p.1, grifo nosso).

Verifica-se que, apesar das críticas e trabalhos sobre a necessidade de reformulação do ensino de física, dados os baixíssimos índices dos alunos nessa disciplina, bem como da necessidade de ações voltadas às políticas educacionais sobre ciências, há, ainda, uma insistência alienada e enviesada em se trabalhar a repetição de exercícios, contra as propostas inovadoras a esse modelo de ensino estático. Concordamos com a importância relatada pelos autores de que é preciso que o aluno faça conexões mentais, entretanto, os mecanismos para que isso ocorra não são objeto de ensino nas salas de aula, nem estão presentes nos livros didáticos.

Dado o contexto apresentado até o momento e, assumindo que obras literárias, em geral, representam a cultura de uma sociedade, com seus aspectos sócio-históricos, e levando

\footnotetext{
${ }^{3}$ Entrevista na integra:

$<\mathrm{http}$ ://www.sbfisica.org.br/v1/index.php?option=com_content\&view=article\&id=538:artigos-da-rbef-discutempresente-e-futuro-do-ensino-da-fisica\&catid=143:marco-2014\&Itemid=315>. Acesso: 08 mai. 2017.
} 
em conta que em nossa sociedade atual, a ciência e a tecnologia estão presentes no cotidiano, torna-se necessário pesquisar até que ponto os aspectos presentes nas obras literárias podem contribuir para o ensino e aprendizado da física. Essas constatações nos levam a questionar quais são os aspectos presentes na literatura e leitura de textos, e suas relações com o processo de formação e desenvolvimento de conceitos físicos pelos alunos de EM.

Uma possível resposta a essa indagação parece estar no desenvolvimento da abstração, sendo necessário investigá-la sucintamente a seguir.

\section{I.2 A abstração como função psicológica superior}

É certo que muitos alunos, senão todos, consideram que o aprendizado da física é difícil, alegando que não compreendem o enunciado dos problemas. É comum constatarmos dificuldades quanto à interpretação dos dados e desenvolvimento de uma solução, o que aponta para a necessidade de alta abstração para a compreensão dos conceitos físicos. Paradoxalmente não há em nenhum livro didático, seja de EM ou de ES, qualquer capítulo que ensine a abstrair, ou seja, ao se abrir um livro de física o aluno não tem respaldo para que possa desenvolver sua abstração e a formação de conceitos físicos, principalmente pelo fato de que a abstração não é objeto de ensino, o que leva a um impasse em relação ao ensino e aprendizagem da física, dado pela necessidade da abstração e sua ausência como objeto de ensino, ou pior, pela falsa concepção de que ela esteja posta e pronta aos alunos quando vão estudar física desde a primeira vez.

Nesse aspecto, Vygotsky (1994; 2008) aprofunda-se, juntamente com seus colaboradores, nos caminhos que levam a formação de conceitos nas crianças, apresentando a maneira como generalizações se transformam em pseudoconceitos e como esses, através da abstração, conduzem à formação de conceitos científicos. Na busca da trajetória da formação de conceitos, Vygotsky (2008) demonstra as fases e subdivisões da forma como aparecem os conceitos, lembrando que: "a formação de conceitos é o resultado de uma atividade complexa, em que todas as funções intelectuais básicas tomam parte" (VYGOTSKY, 2008, p. 72-73). Dentre as etapas de formação de um conceito, Vygotsky (2008) descreve os quatro estágios necessários à formação de um conceito genuíno ${ }^{4}$, são eles:

a) Agregação desorganizada ou "amontoado" que forma uma imagem instável;

b) Pensamento por complexos, onde se configura um agrupamento concreto de objetos unidos por ligações factuais, que necessita de unidade lógica, uma vez que não é formado no plano do pensamento lógico abstrato e subdivide-se em complexo associativo, complexo de coleções, complexo em cadeia, complexo difuso e o pseudoconceito, sendo este, considerado como a ponte entre os complexos e o estágio fi-

\footnotetext{
${ }^{4}$ Para Vygotsky $(1994 ; 2008)$ um conceito genuíno só surge quando os traços abstraídos são novamente sintetizados e a abstração sintetizada daí resultante se torna o principal instrumento de pensamento, sendo a palavra a principal responsável por esse processo.
} 
nal e mais elevado do desenvolvimento da formação de conceitos, porém, continua sendo apenas um pensamento por complexo que necessita de desenvolvimento;

c) Pré-conceito, definido como um pensamento por conceitos potenciais que representa uma abstração isolante, verificada, por meio de treinos, tanto em animais quanto em crianças $e$;

d) A abstração, considerada uma das funções psíquicas superiores, ao lado da memória lógica, atenção deliberada e a capacidade de comparar e diferenciar, ela representa uma capacidade mental que só tem início a partir da adolescência, sendo considerada a principal responsável pela formação de um conceito genuíno (VYGOTSKY, 2008, p. 77-99).

Ainda segundo esse autor, as investigações sobre a formação de conceitos científicos apontam para um fato novo, de relevância fundamental, que pode ser resumido pela dificuldade do adolescente de aplicar um conceito apreendido e formulado em nível abstrato, em novas situações concretas que necessitem ser formulados nos mesmos termos abstratos, indicando que essa superação é: "um tipo de transferência que em geral só é dominado no final da adolescência. A transição do abstrato para o concreto mostra-se tão árdua para o jovem quanto a transição primitiva do concreto para o abstrato" (VYGOTSKY, 2008, p. 100-115, grifo nosso).

Talvez, esteja aqui o ponto central da dificuldade de nossos alunos em estudar física. $\mathrm{O}$ que torna, inclusive, válido questionar a forma como se vem ensinando a física para, principalmente, adolescentes do EM, uma vez que podem não possuir o desenvolvimento cognitivo necessário, como alertado por Vygotsky (2008). É valido lembrar que esses alunos estudam física, em geral, dos 14 aos 17 anos, portanto, antes da vida adulta. Se os estudos apontados por Vygotsky (2008) estiverem corretos, torna-se urgente repensar e reformular a forma como a física vem sendo ensinada nas salas de aula de EM. Sobre essa questão é importante ressaltar que a revisão sobre os trabalhos de Piaget, realizada por Chiapetta (1976, apud GASPAR 2004), indica que mesmo na fase adulta, muitos indivíduos não possuem desenvolvido o estágio operatório formal, caracterizado pelo desenvolvimento da abstração. Se mesmo alguns adultos não possuem as funções psíquicas superiores formadas, o que dizer dos adolescentes estudantes do EM? Uma alternativa seria apresentar a física em contextos culturais mais amplos que aqueles apresentados e resumidos em simples formulações matematizadas sobre os conceitos físicos, a fim de proporcionar o desenvolvimento dessas funções através da leitura, possibilitando elevar o nível de abstração dos estudantes até o uso operacional presente nos livros e apostilas.

Nesse contexto, entendemos que o uso da leitura como potencializadora da formação de conceitos físicos pode encontrar respaldos em sua utilização como um registro de representação semiótica. De acordo Duval (1993; 2005 e 2009), a língua natural, ou materna, é a representação semiótica por excelência, constituindo-se como o primeiro contato do estudante com qualquer conhecimento. A respeito de sua utilização, como uma representação semiótica, faz-se necessário que a leitura possa ser mobilizada para outros registros de representação, 
como uma escrita algébrica, uma tabela, um gráfico, uma ilustração, uma função, entre outras, por meio da conversão de representações de um registro em outro, dado suas especificidades. Uma vez que o tratamento de cada registro é diferente, isto é, a forma de interpretação e operacionalização dos registros, é necessário converter adequadamente um registro em outro (DUVAL, 1993; 2005 e 2009).

Outra possibilidade do uso da leitura é por meio da importância da palavra como formadora de um conceito físico, nesse sentido, encontramos em Vygotsky (2008) o pseudoconceito como uma primeira impressão que o aluno tem sobre a leitura realizada, possibilitando um entendimento inicial, que trabalhado didaticamente pelo professor pode se transformar em um conceito científico. Em ambas as utilizações, justifica-se a formação e desenvolvimento da abstração por meio da leitura.

Nessa perspectiva, a formação de um conceito se constitui como atividade complexa, onde todas as funções intelectuais são necessárias, porém insuficientes se não se utiliza do signo, da palavra, cuja utilização é causa psicológica da transformação radical pela qual passa o processo intelectual no início da adolescência. Isso permite delinearmos o seguinte questionamento: Quais caminhos constituem a formação de um conceito? Vygotsky $(1994 ; 2008)$ responde que todas as funções psíquicas superiores são processos mediados que levam à formação dos conceitos. Os signos constituem o meio básico para dominar e dirigir essas funções; o signo mediador é incorporado à sua estrutura como uma parte indispensável, na verdade, a parte central do processo como um todo. Na formação de conceitos, esse signo é a palavra, que desempenha papel de meio na formação de um conceito e, posteriormente, tornase o seu símbolo. Como nos lembra Braga (2010), para Vygotsky, qualquer função psicológica superior - a atenção voluntária, a abstração, a memória lógica, a formação de conceitos - é externa, isto é, baseia-se na relação social entre os indivíduos humanos, sendo que o seu desenvolvimento ocorre na relação interpsicológica e intrapsicológica do sujeito, ou seja, primeiro no social, entre as pessoas, para, posteriormente, ser compreendida em seu interior (BRAGA 2010).

Como se percebe na teoria interacionista de Vygotsky, a palavra é fundamental para operar a construção de um conceito. O que nos leva de volta à importância da interface físicaliteratura por oferecer a leitura e a interpretação da palavra como signo semiótico operante na transformação de um pseudoconceito, adquirido pela leitura, em conceito físico genuíno. Aqui é válido lembrar que a Organização para a Cooperação e Desenvolvimento Econômico (OCDE), indica a leitura como prioritária a todos os países membros, pelo fato de que o desenvolvimento do hábito de ler desenvolve no indivíduo a capacidade de compreender e interpretar uma grande variedade de textos, dentre eles os científicos, além de relacionar o que foi lido em diversos contextos, possibilitando uma atuação maior na sociedade (OCDE, 2000).

Entendemos, neste contexto, que a leitura e interpretação de textos podem levar ao desenvolvimento de um pensamento abstrato, que pode ser conduzido ao desenvolvimento da 
abstração científica. Mas, o que é a abstração? Como defini-la? Qual ou quais os meios que levam ao desenvolvimento dessa importante função psicológica? Sobre essa problemática, isto é, como desenvolver a abstração, é importante ressaltar que Vygotsky (2008), apesar de indicar as passagens da formação de conceitos, findando-as com a abstração, como último e mais importante estágio para formação de um conceito genuíno, não trata especificamente da abstração. Como abstrair, ou, fornecer elementos para os alunos desenvolverem sua abstração? Tal questionamento constitui uma lacuna, ainda não preenchida pela área de ensino de física.

Dada a importância da abstração, como principal responsável para formação de conceitos, analogamente, a abstração científica se torna fundamental para formação de conceitos científicos. Nesse sentido, encontramos em Khlyabich (1967) uma definição e explicação sobre a abstração científica. Segundo o autor a abstração científica é uma:

Operação por meio da qual a nossa mente, depois de distinguir os caracteres essen-
ciais de um grupo de fatos, separa-os das propriedades secundárias para generali-
zá-los. Por meio de abstrações científicas, o conhecimento passa da percepção de
coisas isoladas à generalização de uma massa de fatos, formulando conceitos, cate-
gorias e leis que refletem os vínculos essenciais internos dos fenômenos. Só a gene-
ralização teórica permite ao pensamento humano pôr a descoberto a essência dos
fenômenos, as leis do seu desenvolvimento. A impossibilidade de conhecer o geral
por outro meio que não seja a abstração não significa que ele não seja real, que
não exista. A lei da gravitação universal não pode ser fotografada, mas, nem por is-
so, podemos negar a sua realidade. A abstração científica materialista é diametral-
mente oposta à abstração idealista que separa o pensamento humano da realidade
objetiva (KHLYABICH, 1967, p. 99).

Assim, a leitura pode propiciar a capacidade de abstrair, uma vez que o leitor abstrai a fala das personagens, os cenários, as paisagens e todas as descrições presentes na literatura lida. Permite que se generalize um conceito abstrato em outras situações futuras, inclusive na resolução matemática, pois o aluno já abstraiu o significado daquela palavra e poderá operá-la em diversos contextos. Entretanto, o mesmo ganho não é garantido se optarmos apenas pelo método de resolução mecânica de exercícios. Muitas vezes, verifica-se que o aluno consegue a nota necessária para ser aprovado, mas não compreende, de fato, o que ele fez. Se for questionado sobre alguma relação que necessite generalização conceitual do que acabou de fazer, geralmente, ele, o aluno, não conseguirá generalizar. Portanto, não abstraiu o que deveria.

Tal dificuldade já foi apontada por Robilotta (1988), como a sensação de que os estudantes estudam, aprendem, mas parecem não saber física:

Essa sensação aparece com frequência durante as nossas atividades relacionadas ao ensino de Física. É comum que mesmo alunos inteligentes e dedicados terminem os cursos com a impressão de que as longas horas de trabalho e todo o esforço empregado no estudo não são recompensados com alguma forma sólida de co- 
nhecimento. Parece que os cursos não fornecem aos estudantes a capacidade de andarem com as próprias pernas, de terem independência. Eles podem aprender a enfrentar os problemas e as situações que foram abordadas durante as aulas, mas ficam completamente sem iniciativa quando colocados frente a problemas novos. $O$ conhecimento discutido no quadro negro não se ajusta ao mundo em que o estudante vive, ele não se enquadra na vida real. $O$ ensino não parece levar os estudantes a serem proprietários do conhecimento. É como se, depois de muito estudo, esses alunos fossem não mais do que portadores de um saber cujos donos seriam os professores, os livros ou a escola (ROBILOTTA, 1998, p. 7, grifos nossos).

A fim de evitar essa falta de significação, essa sensação de vazio, criticada acima, devemos entender como se dá a formação de conceitos científicos.

\section{I.3 O desenvolvimento de conceitos científicos}

As conclusões gerais a que chega Vygotsky (2008), ao investigar as etapas de formação de um conceito, indicam haver complexidade nessa construção, isto é, não obedece a um sistema lógico, definido e linear, por mero método cartesiano, ou por repetições de exercícios. A formação de um conceito é recorrente, o seu processo é anelar, dentro de um movimento do pensamento que oscila entre o particular e o geral e, vice-versa. O pensamento complexo se preocupa em refletir sobre os fenômenos onde interagem muitos fatores, onde se combinam princípios de regulação e de desequilíbrio, onde comparecem contingências e determinismo, criação e destruição, ordem e desordem, onde podem ser identificados níveis de organização e dinâmicas não lineares marcadas por aquilo que se chamam retroações entre esses níveis (FIEDLER-FERRARA, 2010).

Assim, meras associações não formam um conceito, sendo necessário que haja uma operação intelectual em que todas as funções mentais estejam envolvidas na combinação das partes com o todo e do todo com as partes. Isso se torna possível pelo uso das palavras como elemento para ativar e estabelecer as funções psíquicas superiores, como a atenção, a memória lógica e abstração de determinados fatores, que depois de sintetizados se tornam símbolos por meio de um signo, o que permite ao sujeito utilizá-lo em operações abstratas futuras.

Por meio desse processo, acreditamos evidenciar a tarefa árdua que leva à construção de um conceito genuíno. Que dificuldades e limites de capacidade intelectual, devido à idade, passam nossos adolescentes ao se depararem com os conteúdos científicos na escola? Tornase evidente a necessidade de se construir, primeira e criteriosamente o símbolo, para depois utilizá-lo em um processo de ensino e aprendizagem. Nesse contexto, é preciso verificar, também, como se formam os conceitos científicos. Dada essa necessidade, Vygotsky (2008, p. 103) questiona: "O que acontece na mente da criança com os conceitos científicos que lhe são ensinados na escola? Qual é a relação entre a assimilação da informação e o desenvolvimento interno de um conceito científico na consciência da criança"? 
Para Vygotsky (2008), um conceito é mais do que a soma de conexões e associações, sendo um verdadeiro ato real e complexo de pensamento, necessitando desenvolvimento, conforme ressalta ao afirmar que:

Um conceito é um complexo e genuíno ato de pensamento, que não pode ser ensinado pelo constante repisar, antes pelo contrário, só pode ser realizado quando o próprio desenvolvimento mental da criança tiver atingido o nível necessário. Em qualquer idade, um conceito encarnado numa palavra representa um ato de generalização. Mas o significado das palavras evolui e, quando a criança aprende uma nova palavra, o seu desenvolvimento mal começou: a princípio a palavra é uma generalização do tipo mais primitivo; à medida que o intelecto da criança se desenvolve é substituída por generalizações de tipo cada vez mais elevado - processo este que acaba por levar à formação dos verdadeiros conceitos. O desenvolvimento dos conceitos, dos significados das palavras, pressupõe o desenvolvimento de muitas funções intelectuais: atenção deliberada, memória lógica, abstração, capacidade para comparar e diferenciar. Estes processos psicológicos complexos não podem ser dominados apenas através da aprendizagem inicial. [...] A experiência prática mostra também que é impossível e estéril ensinar os conceitos de uma forma direta. Um professor que tenta conseguir isto, geralmente não obtém qualquer resultado, habitualmente mais não consegue da criança do que um verbalismo oco, um psitacismo que simula um conhecimento dos conceitos correspondentes, mas que na realidade só encobre um vácuo (VYGOTSKY, 2008, p. 104, grifos nossos).

Verifica-se, em uma primeira análise, que a tentativa de se ensinar de forma direta novos conceitos aos alunos constitui uma incoerência que pode ser, inclusive, constatada na atualidade. Não será difícil analisar, na grande maioria dos livros didáticos de física, seja de EM ou ES, essa persistência, que repercute claramente na sala de aula por parte do professor, uma vez que sua ação, muitas vezes, não passa da reprodução dos conteúdos existentes nesses livros, assim como da ideologia destes. Parece que não há a percepção desse método inócuo, pois a física ainda hoje é ensinada por repetição de exercícios (BRASIL, 1998). A noção de obstáculo pedagógico (BACHELARD, 1996) ainda é desconhecida pelos professores, que, geralmente, insistem em inserir conceitos novos, palavras novas, aos alunos de forma direta. Como exemplo, pensemos na palavra superposição. Pensemos agora em um professor em uma sala de aula de EM explicando a estranheza da superposição quântica, juntemos a esta palavra outras como colapso de onda, medição quântica etc. A linguagem nesse exemplo se torna um problema crucial, pois além de poder se tornar entediante para os alunos, tais conceitos não têm significado, são palavras vazias, pois não pertencem ao horizonte dos conceitos prévios (BACHELARD, 1996) desses alunos.

Tal é a importância de se evitar ensinar novos conceitos de forma direta aos alunos, que Tolstoy apud Vygotsky (2008) se empenha em comprovar essa inutilidade, ao afirmar que um estudante: 
Quando houve ou lê uma palavra desconhecida, numa frase quanto ao resto compreensível, e depois a lê noutra frase, começa a fazer uma vaga ideia do novo conceito; mais tarde ou mais cedo sentirá... necessidade de usar a palavra - e uma vez. que a use, passa a assenhorear-se da palavra e do conceito. Mas estou convencido de que é impossível transmitir deliberadamente novos conceitos ao aluno... tão impossível e fútil como ensinar uma criança a andar apenas pelas leis do equilíbrio ... (TOLSTOY, L. apud, VYGOTSKY, 2008, p. 105, grifos nossos).

Entendemos que, nesse contexto, a leitura proporcionará um caminho de construção aos conteúdos físicos, permitindo transformar o conceito lido em uma narrativa em conceito científico aceitável e palpável ao aluno de forma a aderir ao novo ensinamento, construindo seus conceitos científicos. Nesse aspecto, Bachelard (1996), recorda que, "parece que nenhuma experiência nova, nenhuma crítica pode dissolver certas afirmações primeiras. No máximo, as experiências primeiras podem ser retificadas e explicitadas por novas experiências" (BACHELARD, 1996, p. 52).

Nesse sentido, as experiências primeiras formadas pela leitura podem ser transformadas, após um desvio, no ensino de conceitos físicos, pois verificamos a importância dada à linguagem no estudo e formação de conceitos científicos. As ciências construíram suas próprias linguagens, plenas de símbolos e códigos. As linguagens são sistemas simbólicos, com os quais recortamos e representamos o que está em nosso exterior, em nosso interior e na relação entre esses âmbitos; é com eles também que nos comunicamos com os nossos iguais e expressamos nossa articulação com o mundo. $\mathrm{O}$ desenvolvimento da linguagem física pode ser obtido, não diretamente, pois se tornaria palavra oca, conforme Vygotsky (2008), contudo, ao trabalharmos as leituras e narrativas presentes na literatura, estaremos proporcionando aos alunos um acesso a essa linguagem de forma indireta, mais suave e prazerosa, possibilitando uma aceitação posterior para tratamento formal dos conteúdos físicos.

Vygotsky (2008) nos esclarece que o principal erro contido na concepção de que o desenvolvimento interno de conceitos científicos pelos alunos seja igual a sua experiência cotidiana, reside no fato de que o conhecimento sistemático necessite de escolarização. Ou seja, não se aprende conceitos científicos por meio de experiências cotidianas. Basta lembrar que não temos uma alfabetização científica instaurada na sociedade, portanto, aprendemos conceitos científicos na escola, com o ensino formal. É processo escolar que o tipo de desenvolvimento intelectual pode ser levado à abstração necessária à geração de um verdadeiro conceito científico. Ressaltamos aqui, novamente, a crucial importância do papel mediador do professor, ao estabelecer uma ponte, uma transposição didática entre conteúdos e alunos.

Os experimentos apresentados por Vygotsky (2008) mostram que é durante o início do aprendizado escolar que nascem, como embriões, as funções intelectuais superiores, que mais tarde resultarão na aquisição de um conceito científico. Ressalta o fato de que certas operações mentais só são possíveis de serem manipuladas quando somos capazes de dominálas. Estabelece que os conceitos científicos, por meio de seu sistema hierárquico de interrelações, parecem formar o meio pelo qual a consciência e o domínio se desenvolvem, para, 
mais tarde, serem transferidos para outros conceitos e outras áreas do pensamento, ou seja, estabelece que a consciência reflexiva surge por meio dos conceitos científicos.

Nessa perspectiva, Vygotsky (2008) observa que um conceito se submete à consciência e ao controle deliberado apenas quando começa a fazer parte de um sistema. Para o autor, a consciência como generalização leva a formação de um conceito supra-ordenado, que inclui o conceito específico. O conceito supra-ordenado leva à existência de conceitos subordinados, o que pressupõe uma hierarquia de conceitos de diversos níveis de generalização. Assim se estabelece um sistema. Vygotsky (2008) nos explica que os conceitos científicos adquiridos na escola têm relação com um objeto, que é mediado por outro conceito, como esclarece:

Assim, a própria noção de conceito científico implica uma certa posição em relação a outros conceitos, isto é, um lugar dentro de um sistema de conceitos. É nossa tese que os rudimentos de sistematização primeiro entram na mente da criança, por meio do seu contato com os conceitos científicos, e são depois transferidos para os conceitos cotidianos, mudando sua estrutura psicológica de cima para baixo (VYGOTSKY, 2008, p. 116, grifos nossos).

A apropriação desses conceitos abstratos é o que leva ao domínio de um conceito científico, é o que permite generalizar fenômenos para outras áreas do conhecimento. Vygotsky (2008) nos relata a dificuldade dos estudantes em abstrair, principalmente quanto à escrita, pois os motivos para escrever são mais intelectualizados, necessitam de um rigor, de uma sistematização, que é mais distante da necessidade imediata, a saber, a fala. Ao escrever criamos situações ou representações, o que exige abstrair-se do mundo real. A escrita reclama, de quem o faz, um domínio da consciência para que se faça uso adequado dos símbolos necessários à sua existência. $\mathrm{O}$ uso da escrita, provêm da prática de leitura. Ao reforçar o hábito de leitura nos alunos, espera-se que abstraiam mais e, com isso, passem a desenvolver melhor a escrita e a capacidade de entendimento dos conceitos físicos. Decorre dessa prática, ou a falta dela, a problemática citada anteriormente, que se resume na possível imaturidade abstrata dos estudantes, uma vez que o aprendizado de conceitos científicos exige, como já discutido anteriormente, funções psíquicas superiores que só se estabelecem, de fato, ao final da puberdade e início da vida adulta.

Isso levou Vygotsky (2008) a investigar a relação temporal entre os processos de aprendizado e o desenvolvimento das funções psicológicas correspondentes, uma vez que o aprendizado geralmente precede o desenvolvimento. Ou seja, o aluno se depara com um conceito científico, ou lhe é exigido trabalhar com conceitos científicos abstratos, antes que seu desenvolvimento psicológico natural tenha se estabelecido. A esse respeito, Vygotsky ressalta o fato de que:

Quando a criança aprende alguma operação aritmética ou algum conceito científico, o desenvolvimento dessa operação ou conceito apenas começou. O nosso estudo 
mostra que a curva do desenvolvimento não coincide com a curva do aprendizado escolar; em geral, o aprendizado precede o desenvolvimento (VYGOTSKY, 2008, p.127, grifo nosso).

Com isso, Vygotsky (2008) descobre que o desenvolvimento intelectual não é compartimentado de acordo com tópicos, ou conteúdos, do aprendizado. Seu percurso é muito mais unitário, sendo que as diferentes matérias escolares, entre elas as que possuem leituras, interagem contribuindo nesse aprendizado em algum momento futuro, quando o aluno tenha maior maturidade. Nesse contexto, torna-se relevante lembrar que o excessivo recurso de se ensinar física por meio de exercícios mecânicos de repetição, que não exijam mais que aplicar determinadas equações, traduz-se em direcionar o aprendizado para os pontos fracos dos alunos, impedindo e atrasando o desenvolvimento de suas funções psíquicas superiores. Por outro lado, a apresentação da física, em um contexto cultural mais amplo, pode propiciar a esses mesmos alunos que criem seu aprendizado baseado em seus pontos fortes, possibilitando a eles encontrar recursos diversos para o desenvolvimento de seu aprendizado em física, ou, em outras palavras, permite uma diversidade de registros de representações semióticas (DUVAL, 2009) em seu aprendizado.

Por fim, os estudos de Vygotsky (2008) a respeito do desenvolvimento dos conceitos científicos, indicam que há ausência de um sistema, ou seja, a falta de diferença psicológica principal que distingue os conceitos espontâneos, como aqueles obtidos pela interpretação textual, dos conceitos científicos. A disciplina formal dos conceitos científicos, por meio da mediação do professor de física, transforma gradualmente a estrutura dos conceitos cotidianos e ajuda a organizá-los no necessário sistema, o que promove o estudante para níveis mais elevados de desenvolvimento. Essa mediação pode promover, também, a generalização dos conceitos científicos apreendidos para situações diversas por meio de uma superação dos elos estruturais presentes na interface física-literatura, o que ocorre com a passagem para um plano de maior generalidade, que contenha e possa reger ambas as generalizações. Apesar das relações complexas internas, entre os conceitos cotidianos e os conceitos científicos, verifica-se que os conceitos físicos são produto do aprendizado escolar, portanto, de responsabilidade do professor de física e suas metodologias.

Vale lembrar que Menezes, Kawamura e Hosoume (1994) alertam que os objetos e objetivos no aprendizado da física se confundem com seu principal problema, que representa a seleção de propriedades e estabelecimento de critérios, que não são desenvolvidos juntamente com os alunos. Ou seja, o ensino de física vem pronto, como uma receita, que basta usar, para logo se obter o produto desejado, em geral, a solução de um problema, por meio da aplicação de alguma expressão matemática. Para os autores, essa atitude produz uma lacuna formativa ao se omitir ou ao deixar de ensinar o próprio processo de produção da abstração, essencial à ciência, como retratam:

Na construção dessa ciência, a abstração que corresponde a simplicidade decorre de um longo processo, por vezes secular, que é a própria ciência em seu desenvol- 
vimento. Também a construção do conhecimento individual, no aprendizado da ciência, decorre de um outro processo, em vários aspectos diferente do primeiro, semelhante em pelo menos um ponto: abstração nenhuma faz qualquer sentido na ausência dos objetivos específicos, variados, "reais", a partir dos quais foi possível o abstrair. Para a ciência e para seu aprendiz, o símbolo precisa primeiro, ser criteriosamente construído, para só então, ser utilizado. Além disso, não pode ser reificado a ponto de substituir o que simboliza, ou a estátua de santo vira santo... (MENEZES; KAWAMURA; HOSOUME, 1994, p. 16, grifo nosso).

Verifica-se que esse processo de produção da abstração, mencionado acima, está, em geral, ausente dos bancos escolares e das aulas de física, o que se dá, principalmente, pela falta de construção simbólica junto aos nossos estudantes, que se deparam com símbolos e signos científicos desconhecidos.

A fim de evitar esse vácuo de compreensão, nossa proposta de inserir a interface física-literatura no ensino da física, como uma ferramenta didática, será apresentada a seguir, onde investigamos a formação de conceitos de Mecânica Quântica (MQ) no EM, utilizandonos dessa interface e apoiando-nos nas discussões anteriores.

\section{Metodologia}

Os pontos discutidos anteriormente tiveram como objetivo preparar-nos para apresentar e analisar a forma como inserimos a interface física-literatura como ferramenta didática, trabalhando com os alunos a construção de conceitos físicos, através da transformação dos pseudoconceitos em conceitos de FMC, em especial, de MQ, presentes em Gilmore (1998), no livro Alice no País do Quantum, o qual já foi utilizado por Pereira e Londero (2013) no ensino de partículas elementares, sendo sugerido, também, por Carvalho e Zanetic (2004) como recurso para o ensino da FMC.

Quanto ao ensino de FMC, torna-se relevante lembrar que vários estudos já investigaram os motivos da sua não inserção no aprendizado dos alunos, além de proporem soluções para sua aplicação. Citamos, com o propósito de amostragem, alguns destes estudos, como a dissertação de Brockington (2005), cuja proposta foi inserir uma sequência didática para alunos da rede pública, objetivando introduzir conceitos da FMC como a dualidade ondapartícula, além de abordagens filosóficas que elevaram a imaginação e abstração dos estudantes. O trabalho de Custódio Pinto e Zanetic (1999) apresenta a FQ por meio de elementos culturais mais amplos como a arte, a música e a pintura, vindo a compor, segundo os autores, uma estratégia didática capaz de apresentar a física pertencente a cultura. Na dissertação de Ferreira (2004), a autora propõe o ensino da física das radiações para alunos adultos da modalidade EJA (Educação de Jovens e Adultos), utilizando de textos de divulgação científica que contenham o conceito de radiação. O trabalho apresentado por Greca, Moreira e Herscovitz (2001) visou propor o ensino da MQ para turmas de engenharia por meio de uma abordagem fenomenológica-conceitual. Os autores apontam para necessária mudança na forma de se en- 
sinar FQ para turmas de licenciatura, ressaltando que para o EM abordagens históricofilosóficas ou computacionais poderiam superar a necessária matemática para o entendimento da MQ neste segmento. Dominguini (2012) realiza uma análise dos livros didáticos de física, disponibilizados pelo Programa Nacional do Livro Didático do Ensino Médio (PNLEM), com o intuito de verificar como e se a FM aparece nestes livros. Constata-se neste trabalho que os autores dos livros didáticos discordam sobre a importância da FM, dado que a mesma aparece em algumas obras e outras não. Segundo Dominguini (2012), os conteúdos da FM, quando presentes nos livros, constam apenas dos últimos capítulos, alertando para necessária compreensão da importância deste ensino nos livros didáticos de física. A pesquisa realizada por Melhorato e Nicoli (2012) propõe experimentos de baixo custo para demonstração da quantização de energia; do modelo corpuscular da luz e, da condução de eletricidade em sólidos para alunos do EM. Menezes (2000) aborda as diretrizes que nortearam a elaboração dos novos Parâmetros Curriculares Nacionais para o ensino de física, alertando para a necessidade de ampliação do ensino tradicional da disciplina para a ideia de uma física como cultura ampla capaz de construir uma visão de mundo científica. Em Ostermann e Moreira (2000) encontramos uma revisão bibliográfica sobre FMC no EM. Segundo os autores, há uma escassez de propostas que avaliem aplicação em sala de aula com resultados sobre aprendizagem. Pessoa Júnior (2003), apresenta um livro com abordagem conceitual e filosófica das interpretações da FQ, utilizando-se de uma linguagem menos matemática, constituindo-se referencial importante para formação de professores. Pietrocola e Siqueira (2006) apresentam uma sequência didática que envolveu o ensino de partículas elementares ao EM sob a ótica da transposição didática. Terrazan (1992) fortalece a necessidade de se repensar a formação inicial dos professores nos cursos de licenciatura, para que tenham a necessária formação sobre FMC a fim de que possam, futuramente, nas salas de aula, ensinar estes conteúdos.

A lista é grande, e visamos aqui apenas ilustrar algumas propostas e trabalhos pesquisados sobre a inserção da FMC no EM. Da lista apresentada acima, salientamos que se propõem alternativas didáticas para superar a necessária matemática para o aprendizado da FMC. Nesse contexto, nossa proposta é demonstrar que os pseudoconceitos criados através da leitura sobre os conceitos de MQ pelos alunos de EM foram articulados didaticamente de forma a permitir a abstração científica (KHLYABICH, 1967). Buscamos, também, mostrar que tanto o ensino de MQ, quanto a interface física-literatura não estão presentes, de fato, nas salas de aula de física do EM, ao menos quando comparadas com a Mecânica Clássica.

Os alunos participantes da pesquisa eram do $3^{\circ}$ ano do EM, totalizando 46 sujeitos, pertencentes a uma escola privada da zona sul de São Paulo, cujo professor, que aceitou a realização da atividade com seus alunos era licenciado em física e possuía 15 anos de experiência como docente. Toda a etapa de leituras, construção de conceitos físicos mediados pelo professor e a avaliação, demandaram 6 aulas duplas, ou seja, um total de 12 aulas de 50 min cada. As leituras empregadas foram divididas em quatro partes e todas realizadas pelo professor, em aula, juntamente com seus alunos. A primeira correspondeu ao capítulo XVIII - Fei- 
ticeiros e Aprendizes - da Era dos Extremos de Hobsbawm (1995), com intuito de avaliar a compreensão dos alunos dentro dos contextos: social, político, histórico e filosófico. Esse capítulo consistiu de 17 páginas, as quais foram distribuídas cópias e lidas em sequência pelos alunos, conforme seus números de chamada, parágrafo por parágrafo, ou seja, o professor da turma fez com que todos os alunos lessem e acompanhassem a leitura do capítulo. As demais partes foram constituídas da leitura, também em sala de aula, dos três primeiros capítulos de Alice no País do Quantum, por comportarem os elementos sobre MQ a serem estudados, enquanto os demais capítulos se aplicavam a outros temas da FMC.

Esses 3 capítulos foram apresentados em slides, sendo que, novamente, foram lidos por todos os alunos, conforme número de chamada, em sala de aula. A metodologia empregada pelo professor consistiu em, durante a primeira leitura, na primeira aula, anotar temas que julgava relevante quanto à construção e surgimento da FQ, bem como aspectos históricofilosóficos e sociais que a leitura fornecia. Já na segunda aula, o professor discutiu com todos os alunos os aspectos presentes naquela leitura, ouvindo e articulando o surgimento da FQ em seu aspecto social, político, filosófico e histórico. As opiniões dos alunos sobre essas e as demais leituras serão analisadas mais adiante.

O livro Alice no País do Quantum foi apresentado alertando-se os alunos de que se tratava de uma analogia, uma representação possível de dar um entendimento primeiro sobre os conceitos físicos da quântica, mas não representava a realidade concreta da FQ. As aventuras de Alice ao longo da narrativa foram expressas como a ficção que elas representam, mas que estabelecem relações com os conceitos físicos. Como forma de aproximação do tema, o professor comentou com os alunos sobre as relações matemáticas presentes na obra Alice no País das Maravilhas, escrita pelo matemático Charles Lutwidge Dodgson, mais conhecido pelo seu pseudônimo Lewis Carroll, que em seu romance aproxima os leitores de conceitos matemáticos mais abstratos. Vale apontar que a proposta de formular proposições argumentativas favoráveis ao uso eficaz de romances matemáticos na construção do conhecimento já foi estudada por Teixeira e Mendes (2006). Na mesma direção, o professor, lembrou aos alunos sobre o romance $O$ Homem que Calculava, de Malba Tahan, heterônimo do professor e matemático Júlio César de Mello e Souza, fornecendo aos alunos a indicação de relações entre os conceitos mais abstratos, com os quais iriam se deparar, mas que também são possíveis de serem entendidos pela leitura.

No mesmo sentido, o professor alertou os alunos para a existência de notas explicativas, mais longas, dispostas nos finais dos capítulos, que esclarecem alguns conceitos. Assim orientados, poderiam ler os três capítulos iniciais sugeridos, com suas várias ilustrações e observar as notas explicativas existentes ao longo da narrativa das aventuras de Alice, a fim de procurarem um significado maior sobre alguns conceitos iniciais. Nessa mesma perspectiva, a terceira e quarta aula foram utilizadas para a leitura coletiva das 14 páginas constituintes do primeiro capítulo do livro, denominado No País do Quantum, a qual, foi interrompida algumas vezes por perguntas dos alunos referentes aos seguintes conceitos: partículas; direção de 
rotação dos elétrons (spin-para cima e spin-para baixo); princípio da incerteza de Heisenberg; princípio de exclusão de Pauli; estados quânticos; distribuição de probabilidade; penetração de partículas e; barreira de energia.

Havíamos solicitado ao professor para, nesses momentos, não responder aos alunos prontamente, fazendo com que eles mesmos, pela sua interpretação da história, criassem algum entendimento e consultassem as notas explicativas presentes nos próprios capítulos. Assim, o professor perguntava aos alunos qual era a interpretação que tinham tido pela própria narração, anotando as dúvidas e as interpretações, para depois serem mediadas por ele.

A leitura das 15 páginas do segundo capítulo, denominado $O$ Banco Heisenberg, decorreu durante a quinta e sexta aula, onde os alunos levantaram dúvidas sobre: energia; momentum; massa de repouso; flutuação quântica; relação de Heisenberg; superposição; constante de Planck; constante de Planck reduzida e; sobre o episódio final, no qual Alice passa por várias portas ao mesmo tempo. A narrativa final do capítulo 2 descreve Alice abrindo diversas portas, observando diversas possibilidades, uma delas é a porta que ela desejava chegar, O Instituto de Mecânica, inclusive, constituinte do terceiro e último capítulo de nosso estudo, cuja leitura das 22 páginas foram realizadas durante parte da sexta aula e toda a sétima aula, gerando as seguintes dúvidas: fenômeno de interferência; experimento da dupla fenda de Young; hipótese de De Broglie; complementaridade; função de onda e; paradoxo de Schrödinger.

Após o término das leituras, verificamos que as dúvidas decorrentes destas geraram pseudoconceitos e possibilitaram o professor construir as aulas proporcionando sentidos aos conceitos físicos da FQ. Nesse contexto, o professor passou a realizar o tratamento e a conversão dos pseudoconceitos surgidos das leituras para os conceitos físicos pretendidos, durante as quatro aulas seguintes, como se verifica na tabela 1 .

Tabela 1: Tratamento e conversão dos registros obtidos pelas leituras pelo professor durante as aulas.

\begin{tabular}{|l|l|}
\hline $\begin{array}{l}\text { Tratamento e Conversão dos } \\
\text { registros obtidos da leitura do } \\
\text { cap. XVIII da Era dos Extremos } \\
\text { de Hobsbawm - Feiticeiros e e } \\
\text { aprendizes }\end{array}$ & $\begin{array}{l}\text { Apresentação do experimento de Michelson-Morley e a inexistên- } \\
\text { cia do Éter, culminando na Relatividade Restrita de Einstein. Apre- } \\
\text { sentação do problema de radiação do corpo negro, levando à tenta- } \\
\text { tiva de unificar Eletromagnetismo e a Termodinâmica, surgindo a } \\
\text { FQ. Debate sobre a 5 5anferência de Solvay e a discussão da teo- } \\
\text { ria quântica. }\end{array}$ \\
\hline $\begin{array}{l}\text { Tratamento e Conversão dos } \\
\text { registros obtidos da leitura do } \\
\text { capítulo 1 - No País do Quan- } \\
\text { tum }\end{array}$ & $\begin{array}{l}\text { Apresentação do vídeo O discreto charme das partículas elementa- } \\
\text { res , definição das propriedades das partículas. Utilização de apli- } \\
\text { cativo Java sobre tunelamento quântico. }\end{array}$ \\
\hline
\end{tabular}

\footnotetext{
5 Disponível em: <https://www.youtube.com/watch?v=o7bIzLLDX7Q\&list=PLOc711-qHCmR6qcVWuM-j_w2 hIvzlQNni>. Acesso em: 10 mai. 2017. Vídeo baseado no livro homônimo de Abdalla (2006).

$6 \mathrm{O}$ aplicativo Java, que trata do tunelamento quântico, pertence à série de aplicativos de simulações interativas do Phet Colorado, presente em: <http://phet.colorado.edu/pt_BR/simulation/quantum-tunneling >. Acesso em: 10 mai. 2017.
} 


\begin{tabular}{|l|l|}
\hline $\begin{array}{l}\text { Tratamento e Conversão dos } \\
\text { registros obtidos da leitura do } \\
\text { capítulo 2 - O Banco Heisen- } \\
\text { berg. }\end{array}$ & $\begin{array}{l}\text { Apresentação dos conceitos e definição dos termos e propriedades } \\
\text { físicas. Constante de Planck h }=6,63.10^{-34} \mathrm{~J} \text {. s. apresentada como } \\
\text { necessária para a descrição do tamanho dos quanta, os pacotes de } \\
\text { energia emitidos pelos fótons. Já a constante reduzida (h) foi expli- } \\
\text { cada como a constante de Planck dividida por 2 } \pi \text {, dada a órbita } \\
\text { circular dos elétrons, para qual o momento angular é quantizado. E, } \\
\text { a expressão E }=\mathrm{h} \text {. v, foi trabalhada para demonstrar alguns cálcu- } \\
\text { los de energia de fótons. }\end{array}$ \\
\hline $\begin{array}{l}\text { Tratamento e Conversão dos } \\
\text { registros obtidos da leitura do } \\
\text { capítulo 3-O Instituto de Me- } \\
\text { cânica }\end{array}$ & $\begin{array}{l}\text { Exposição do experimento da dupla fenda de Young em vídeo ; } \\
\text { apresentação da dualidade onda-partícula, dualidade da luz e da } \\
\text { matéria; interferências construtivas e destrutivas; definição da } \\
\text { complementaridade de Bohr onde um fenômeno ou é corpuscular, } \\
\text { ou é ondulatório, nunca ambos ao mesmo tempo e; exposição da } \\
\text { superposição por meio do paradoxo do gato de Schrödinger; colap- } \\
\text { so da função de onda e papel do observador. }\end{array}$ \\
\hline
\end{tabular}

Das leituras realizadas e aulas ministradas pelo professor de física, ressaltamos o capítulo três que trata do Instituto de Mecânica, onde Alice se encontra com dois personagens, o Mecânico Clássico e o Mecânico Quântico, que representam, respectivamente, a visão da física clássica e da física moderna. Como uma alusão aos clássicos personagens Simplício e Salviati, de Galileu Galilei, os dois mecânicos apresentam suas explicações a respeito dos fenômenos naturais, enquanto Alice parece representar o personagem Sagredo, que ouve as duas versões e tira suas conclusões. Nessa parte da narrativa, são descritos importantes conceitos físicos para a compreensão da MQ, como a dualidade onda-partícula, cuja importância é ressaltada por Pessoa Junior (2003). Segundo o autor, a FQ apresenta diversas interpretações propostas na literatura científica, sendo que sua essência é a dualidade onda-partícula, conforme descreve: "é a teoria que atribui, para qualquer partícula individual, aspectos ondulatórios, e para qualquer forma de radiação, aspectos corpusculares. Esta é uma versão "geral" da dualidade onda-partícula" (PESSOA JUNIOR, 2003, p. 1, grifo do autor). Ao lerem o capítulo 3, os alunos constataram que na FQ há características ondulatórias também nas partículas. Essa, talvez, seja a grande lição da MQ.

Em geral, após a leitura desse capítulo, os alunos se inquietaram a respeito do motivo da difração de ondas se apresentar de uma forma na explicação do Mecânico Clássico e de outra na explicação do Mecânico Quântico. Também questionaram a razão pela qual Alice, ao olhar por onde os elétrons passavam, percebia que eles deixavam de apresentar interferência. Os alunos também estranharam o conceito de superposição exemplificado pelo gato de Schrödinger, proposto ao final do capítulo.

Analisando os comentários dos alunos, foi percebido que não ocorreu, na realidade, falta de entendimento pela leitura efetuada, entenderam bem a narrativa proposta no terceiro capítulo, além das notas explicativas, constantes ao longo da narração. Eles se mostravam desconfortáveis por não entenderem a razão desses eventos ocorrerem assim. Ou seja, ao final

\footnotetext{
7 Representação proposta em vídeo do youtube que demonstra o experimento da dupla fenda para o elétron. Disponível em: <http://www.youtube.com/watch?v=lytd7B0WRM8>. Acesso em: 10 mai. 2017.
} 
da leitura, e das aulas ministradas pelo professor, os alunos estavam perplexos com a estranheza dos fenômenos quânticos, o que indica certo entendimento inicial dos conceitos oferecidos pela FQ, principalmente se recordarmos a fala de Bohr, apud Gilmore (1998, p. 8): "qualquer um que não tenha ficado aturdido ao pensar na teoria quântica não a compreendeu".

Buscando dirimir algumas estranhezas da FQ, como a dualidade onda-partícula, o professor propôs um problema sobre a equação de onda de De Broglie $\lambda=h / \rho$, solicitando aos seus alunos que determinassem e comparassem o comprimento de onda para um atleta profissional de $80 \mathrm{~kg}$ que corra $10 \mathrm{~m} / \mathrm{s}$, com um elétron de massa $9,1093897.10^{-31} \mathrm{~kg}$ que apresente a velocidade de $3,0.10^{8} \mathrm{~m} / \mathrm{s}$. Os alunos encontraram $\lambda=8,28 \cdot 10^{-37} \mathrm{~m}$ para o comprimento de onda do atleta e $\lambda=2,42.10^{-12} \mathrm{~m}$, ou 2,42 pm (picômetro) para a partícula. Com essa resposta, puderam verificar que o $\lambda$ é inversamente proporcional a quantidade de movimento. Como um corpo macroscópico apresenta massa grande e velocidade baixa não terá onda associada considerável. Contudo, uma partícula com massa pequeníssima e velocidade alta resulta em uma onda não desprezível, como no exemplo dado. Para um elétron a onda equivalente na ordem do picômetro é uma onda considerável para efeitos quânticos.

Interessante apontar que a interface entre a leitura e o cálculo trouxe compreensão sobre a equação de onda de De Broglie. Assim, foi possível, também, aproximar os alunos do pensamento matemático mais abstrato, dando sentido a esse e ligando-o, tanto aos eventos descritos na narração, quanto aos fatos mais concretos e próprios da teoria quântica, permitindo um ganho conceitual muito maior nessa interação por ter proporcionado sentido aos estudantes.

A superposição de estados quânticos, apresentada pelo professor por meio do " $g e$ dankenexperiment" do gato de Schrödinger, objetivou demonstrar que uma partícula pode estar em superposição de estados quânticos, em vários lugares ao mesmo tempo. No caso do gato, vivo e morto ao mesmo tempo, uma vez que ninguém pode observar seu real estado dentro da caixa fechada. Quando um observador realiza uma observação, há o colapso da função de onda e, dada essa interferência, verifica-se a partícula, ou como no caso do "gedanken", constata-se o gato vivo ou morto, mas até lá, ele se encontra em superposição - vivo e morto. Foi explicado aos alunos que a ideia desse "gedankenexperiment" foi mostrar o absurdo que é considerar efeitos quânticos com olhar macroscópico, ou seja, com uma visão da física clássica.

Essa discussão possibilitou inserir a importância do emprego dos experimentos de pensamento utilizados na física ao longo de sua construção. Seu emprego na história da ciência é farto, sendo utilizado dos pré-socráticos à Física Moderna. Tomas Kuhn (1977) ressalta sua capacidade de contribuição para a pesquisa:

Nem é acidental o fato de que em ambos os períodos a chamada experiência de pensamento ter desempenhado um papel tão crítico no progresso da pesquisa. Como mostrei em outros lugares, a experiência de pensamento analítica que é tão importante nos escritos de Galileu, Einstein, Bohr e outros é perfeitamente calculada pa- 
ra expor o antigo paradigma ao conhecimento existente, de tal forma que a raiz da crise seja isolada com uma clareza impossível de obter-se no laboratório (KUHN, 1977, p. 120).

Decerto, os experimentos de pensamento desempenharam um importante papel na história do pensamento científico, possibilitando abstrair conceitos, eventos e fenômenos que, muitas vezes, na prática, seriam muito onerosos, ou difíceis de reproduzir, ou até mesmo impossíveis de se verificarem experimentalmente.

Por fim, ao final do capítulo 3 do livro, há a preparação do leitor para discussão do problema da medida quântica, com a interpretação da escola de Copenhague. Contudo, essa é uma outra etapa, pois nosso objetivo era analisar apenas a contribuição dos três primeiros capítulos na formação de conceitos de MQ. Todavia, vale relatar que muitos alunos terminaram a leitura do livro por conta própria, inclusive buscando explicações com o professor sobre outros conteúdos da FMC.

Com o objetivo de coletar as impressões dos alunos, bem como avaliar a proposta didática abordando a interface física-literatura, além de verificar aspectos referentes ao uso de analogias como recurso para apreensão de conceitos físicos, foi entregue um questionário aberto aos alunos (anexo I) e, como instrumento de avaliação os alunos responderam a um grupo de 17 questões (anexo II) que trataram especificamente da FMC. O número de questões foi estipulado pela escola para todas as disciplinas para compor um simulado e as questões foram, em parte, compostas pelas leituras realizadas pelos alunos e por seleção de questões de vestibulares que continham os tópicos de FMC estudados ao longo daquele bimestre. Ressalte-se que algumas questões (anexo II) contêm tópicos de relatividade, que compunham os estudos da série, mas que não fizeram parte da proposta apresentada neste artigo, portanto, são consideradas para análise apenas as questões de 06 a 17.

\section{Resultados}

As respostas obtidas indicam que os alunos apoiaram o uso da interface como ferramenta de ensino de FMC e elementos de MQ. Compreenderam o caráter abstrato e imaginativo presentes na física, por meio da conversão e transformação da leitura, que criou inicialmente pseudoconceitos, em conceitos físicos adequados pelas aulas ministradas e pelos recursos de TIC (Tecnologia da Informação e Comunicação) utilizados. Mesmo os alunos que manifestaram abertamente não gostar de ler, acharam a proposta interessante, sendo que, para esses, os vídeos apresentados foram mais bem compreendidos, em suas opiniões, uma vez que não precisavam ler. Acharam que apenas assistindo uma interpretação pronta dada pelos vídeos já era suficiente para compreenderem alguns conceitos. Entretanto, a maioria opinou mais favoravelmente à leitura, por permitir melhor abstração dos fenômenos físicos estudados, enquanto outros salientaram a importância da interação entre ambos. 
A fim de melhor avaliar as respostas dos nossos alunos, realizamos uma análise em 6 categorias, o que nos permitiu buscar uma melhor compreensão dos resultados obtidos das respostas dadas ao questionário aberto (anexo I) e às questões de múltipla escolha (anexo II). É importante ressaltar que as categorias foram criadas levando em consideração a sequência da proposta didática aplicada em sala de aula, partindo do aspecto histórico-filosófico à introdução da FMC, para a análise do papel da literatura, da ficção, das representações e, da literatura no ensino da física, finalizando com a verificação dos conteúdos apreendidos pelos estudantes.

Na tabela 2 apresentamos as categorias criadas e seus objetivos.

Tabela 2: Categorias e Objetivos.

\begin{tabular}{|c|c|}
\hline CATEGORIA & OBJETIVO \\
\hline $1^{\mathrm{a}} \mathrm{O}$ cenário Real & $\begin{array}{l}\text { Avaliar a compreensão dos alunos sobre o contexto social, político, } \\
\text { histórico e filosófico da FMC, através da questão } 01 \text { do anexo I. }\end{array}$ \\
\hline $\begin{array}{l}2^{\mathrm{a}} \mathrm{O} \text { papel da literatura no } \\
\text { ensino e aprendizagem da } \\
\text { física }\end{array}$ & $\begin{array}{l}\text { Verificar como os alunos interpretaram o uso da literatura, da leitu- } \\
\text { ra, das narrativas, figuras de linguagem, quanto à melhoria no ensi- } \\
\text { no e aprendizado da física, avaliando de que forma a interface físi- } \\
\text { ca-literatura aproximou-os dos conceitos físicos estudados. Foram } \\
\text { selecionadas as questões } 02,03 \text { e } 07 \text { do anexo I. }\end{array}$ \\
\hline $3^{\mathrm{a}} \mathrm{O}$ cenário Ficcional & $\begin{array}{l}\text { Analisar o papel da imaginação, como ela é importante tanto para a } \\
\text { literatura quanto para a física, avaliando de que forma os alunos } \\
\text { interpretaram e compreenderam a relevância da imaginação na } \\
\text { construção de modelos científicos, e na formação da abstração e } \\
\text { dos conceitos físicos estudados, por meio das respostas às questões } \\
04,05 \text { e } 06 \text { do anexo I. }\end{array}$ \\
\hline $\begin{array}{l}4^{a} \text { Os atores: o papel das re- } \\
\text { presentações no cenário con- } \\
\text { ceitual. }\end{array}$ & $\begin{array}{l}\text { Avaliar de que forma houve a compreensão das analogias e dos } \\
\text { modelos como cenários de construção conceitual dos tópicos de } \\
\text { MQ estudados, além de averiguar se e como os alunos assimilaram } \\
\text { os conceitos ensinados, se por meio da literatura, por meio dos } \\
\text { vídeos ou pela interação entre ambos. Nessa categoria verificamos } \\
\text { as respostas dadas às questões } 08 \text { e } 10 \text { do anexo I. }\end{array}$ \\
\hline $\begin{array}{l}5^{\mathrm{a}} \text { A encenação: a literatura } \\
\text { como ferramenta no ensino de } \\
\text { física. }\end{array}$ & $\begin{array}{l}\text { Verificar se a interface física-literatura se concretizou como uma } \\
\text { ferramenta didática no ensino dos conceitos de MQ, abordados nas } \\
\text { leituras e vídeos, bem como analisar o surgimento dos pseudocon- } \\
\text { ceitos e como esses conceitos se transformaram em conceitos cien- } \\
\text { tíficos pelos exemplos dados nas respostas sobre a questão } 09 \text { do } \\
\text { anexo I. }\end{array}$ \\
\hline $\begin{array}{l}6^{\text {a }} \text { A verificação dos conceitos } \\
\text { físicos apreendidos pelos } \\
\text { alunos }\end{array}$ & $\begin{array}{l}\text { Analisar a consolidação dos conteúdos abordados nesse estudo, na } \\
\text { avaliação de múltipla escolha, anexo II, constatando a conversão } \\
\text { (DUVAL, 2005) da leitura nos conceitos físicos. }\end{array}$ \\
\hline
\end{tabular}

As respostas dos alunos ao questionário são apresentadas abaixo, transcritas sem alteração, o que pode resultar em erros gramaticais que foram mantidos como escrito pelos alunos, além dos grifos serem utilizados como recurso para ressaltar alguns aspectos que serão analisados. É importante apontar que, dadas as limitações de espaço, não apresentamos todas 
as respostas dos 46 alunos a cada uma das questões supracitadas, o que nos levou a um recorte das respostas sem prejuízo de análise para cada uma dessas categorias, sendo que as escolhas são representativas do conjunto.

\section{$1^{\text {a }}$ Categoria}

“Através da explicação do contexto histórico da transição da física clássica para a física moderna foi possível obter um melhor entendimento de como surgiu a necessidade de estudar o mundo quântico" (aluno 09).

"Sim, pois nos possibilitou aprofundar na história da Física Moderna, ou seja, aprendemos mais a teoria e sobre a utilidade da física em nosso cotidiano, o que acaba por facilitar o entendimento e até a resolução de contas" (aluno 36).

"Sim. Foi pertinente, porque através dela pode se ver como foi difícil a aceitação da Física Moderna, que ia contra tudo que os físicos sabiam até então. Apresenta, também, suas principais ideias, seus paradigmas, os estudos realizados por vários físicos e seu impacto sobre a sociedade, conceitos, entre outros, o que tornou a física moderna mais "clara", mais compreensível, o que é difícil no primeiro momento que entramos em contato com ela" (aluno 15).

Das respostas à primeira categoria, notamos que o aspecto histórico, filosófico e social abordado na leitura foi percebido como importante para o desenvolvimento do papel da física em outros contextos culturais. Essa relação permitiu, também, o entendimento dos aspectos da vida cotidiana, além de influenciar positivamente na resolução de aspectos técnicos presentes em exercícios.

\section{$2^{\mathrm{a}}$ Categoria}

"Foi muito útil o uso da literatura nos estudos físicos, principalmente no meu caso que tenho um pouco de dificuldade com matérias exatas, com a leitura consegui absorver muito mais conceitos da física, de modo que me proporcionou maior entendimento da matéria e um aprendizado mais eficiente" (aluno 04).

"A teoria física mesclada a uma história interessante nos ajuda a focar e compreender melhor a matéria que está sendo passada no livro e torna o estudo em algo mais leve e prazeroso" (aluno 13).

"Mesclando a física com a literatura fica mais fácil para compreender e até mais interessante e divertido" (aluno 30).

"A literatura fez com que o meu entendimento sobre a física aumentasse, fazendo, assim, aumentar o meu gosto pela mesma" (aluno 39).

"O uso de outros recursos linguísticos para estudar a física, como leitura e narrativas, faz ser possível imaginarmos um outro mundo onde podemos interagir com a história e esta nova percepção de mundo, em que conseguimos enxergar com clareza o que os físicos tentam explicar através de fórmulas" (aluno 10).

Nessa categoria, as respostas exemplificam que um sentimento de compreensão conceitual dos tópicos de FMC foi potencializado por meio do uso da literatura. Note-se que ape- 
sar de não ser perguntado sobre o prazer em se estudar física, muitas das respostas apontam para esse desencadeamento, o que apoia e reforça a utilização da interface física-literatura como potencial ferramenta ao ensino de física para jovens de EM, permitindo uma visão mais ampla daquela única apresentada por meio de expressões matemáticas.

\section{$3^{\text {a }}$ Categoria}

"A imaginação científica exige uma maior capacidade de imaginação, já que é mais complicado imaginar um fato científico do que um fato ocorrendo em um livro de poesia" (aluno 06).

“Ambas são importantes, na física a imaginação resulta nos modelos, como a representação de um elétron como sendo uma bolinha, mas o elétron não é uma bolinha" (aluno 26).

"A imaginação é fundamental para escrever qualquer tipo de história. No caso da física é necessária muita imaginação para conseguir abstrair os conceitos e tornar isso mais fácil de visualizar a teoria. Abstrair sentimentos e torna-los histórias é tão difícil e importante quanto fazer o mesmo com a ciência e torna-la em teorias" (aluno 13).

"Na literatura usamos a imaginação para criarmos o cenário, as personagens e entre outras coisas. Na física é muito importante a imaginação na hora de resolver um problema, na visualização do enunciado e da resolução" (aluno 39).

"Nos faz viajar, nos ajuda a imaginar as fórmulas" (aluno 20).

“Todos os conceitos físicos só surgem através de cálculos matemáticos após terem passado pela imaginação de alguém antes de concretizá-lo. Sim, pois da mesma forma que quando lemos um livro, imaginamos todo o cenário e os personagens propostos, então, quando vemos conceitos físicos, também podemos imaginar o cenário proposto" (aluno 29).

Pelas respostas fornecidas acima, podemos constatar registros a respeito das representações semióticas e funcionamento cognitivo por meio da conversão, conforme Duval (2005). A fala desses alunos demonstra sua interpretação sobre a formação de conceitos físicos através da literatura, da imaginação e da leitura, o que sugere a abstração dos conceitos físicos estudados. Recordemos que, de acordo com Duval (1993), as representações semióticas, os signos, desenvolvem a comunicação e a cognição, sendo por meio dessas representações semióticas que o aluno exterioriza, comunica e objetiva seu pensamento sobre um ente mais abstrato. Talvez, esse foi o motivo pelo qual alguns alunos exteriorizaram seu pensamento sobre o fato da leitura e da imaginação, constante no enredo da narrativa de Alice no País do Quantum, tenha também melhorado suas compreensões a respeito das soluções de problemas, isto é, comunicaram a conversão da representação semiótica da leitura para a linguagem mais abstrata, física e matemática.

\section{$4^{\mathrm{a}}$ Categoria}

"Sim, elas podem ser usadas como modelos, elas nos ajudaram com a aprendizagem, serviu como base para nos ajudar a entender a física quântica" (aluno 14). 
"Sim, são modelos dos conceitos que nos são difíceis de entender, fazendo com que nós imaginemos as analogias e assim absorvendo o conceito" (aluno 41).

"Podem ser considerados modelos, pois trata de representações impossíveis de serem visualizadas do ponto de vista macroscópico. O princípio da incerteza mesmo comprova isso, e o livro da Alice também, pois ela não consegue conversar com um elétron parado" (aluno 33).

“Ambos os recursos são de extrema importância, pois se o aluno não entende o que lê, o vídeo ajuda à compreensão da teoria ou experimento" (aluno 33).

"Visualizar a animação ajuda ainda mais a entender. Ambos são importantes, cada qual no seu modo, vídeo é válido para quem não gosta de leitura, para quem prefere ler o livro é melhor escolha, porém os dois juntos surtem um efeito muito maior e mais vantajoso para aquele que está aprendendo" (aluno 04).

As respostas dos alunos acima apontam para a validade desse recurso como ferramenta de ensino. Outros trabalhos, como os constantes na edição especial do Journal of Research in Science Teaching, de 1994, que tratam exclusivamente de pesquisas sobre analogias, intitulada "O papel da Analogia na Ciência e no Ensino de Ciência", também salientam a importância desta estratégia didática. Kemper; Zimmermann e Gastal (2010), ou Zambon e Terrazan (2013), avaliam e justificam o uso de analogias para transpor conceitos concretos em abstratos, facilitando o entendimento dos alunos no seu processo de ensino e aprendizagem. Percebemos que a interação metodológica, da apresentação dos conteúdos pelos recursos utilizados, surtiu efeitos positivos e agregadores no aprendizado dos conceitos abordados com os alunos, uma vez que um recurso completou o outro, formando um todo indissociável e complexo de cognição e aprendizado, como bem ressaltou o aluno 04 ao afirmar que: "os dois juntos surtem um efeito muito maior e mais vantajoso para aquele que está aprendendo".

\section{$5^{\text {a }}$ Categoria}

"As leituras me auxiliaram muito no entendimento e aprendizado dos conceitos científicos estudados em sala, de modo que agora, com a leitura dos capítulos do livro Alice no País do Quantum pude ver a explicação de uma forma completamente diferente, que se tornou mais simples e de fácil compreensão, tal como a ideia da superposição de estados quânticos.

A ideia passada pelo livro faz o leitor analisar de uma forma completamente distinta de uma aula com contas e números, ou seja, foi uma ideia brilhante passar esse tipo de atividade para nós, ainda mais nesta matéria que na maioria das vezes é difícil de entender" (aluno 04).

"A utilização das leituras na sala de aula conseguiu me fornecer um ótimo aprendizado sobre o assunto. Fiquei muito satisfeita com o resultado. No livro Alice no País do Quantum, lendo sozinha e depois com a ajuda do professor e seus comentários foi de grande ajuda" (aluno 46).

"Sim. Ajudaram, principalmente o livro Alice no País do Quantum, que além de me ajudar a entender o que era um fóton (pacote de luz, de acordo com o livro), algo que antes da leitura eu não tinha conhecimento, me ajudou a entender mais sobre o comportamento da luz, que 
é dual, por meio da experiência com as fendas, que comprovou essa dualidade, e também o gato de Schroedinger, que também foi representado no livro" (aluno 15).

"Na parte em que os pedreiros estão construindo a casa, me ajudou a ver a profundidade e complexidade do princípio da superposição de estados" (aluno 18).

"Sim. A explicação dada pelo professor sobre o modelo de dupla fenda foi ainda mais esclarecedora após a leitura do capítulo 3 do livro, onde Alice vê esses acontecimentos através de uma sala de pensamentos" (aluno 10).

"Sim, por exemplo, quando Alice vê os tijolos sendo jogados na construção desorganizadamente. Essa parte do texto ajuda na melhor compreensão do comportamento de partículas em termos de distribuição de probabilidades" (aluno 36).

Essas respostas indicam a validade da interface física-literatura como ferramenta de ensino de física, além de demonstrar a satisfação em se estudar física, como salienta o aluno 24, ao lamentar não ter tido essa metodologia anteriormente em seus estudos de física: "Nunca havia tentado esse método. É cansativo, porém, interessante em alguns pontos. É proveitoso não apenas na física quântica. Queria poder ter usado o método em física clássica" (aluno, 24). Verificamos nessas respostas o papel da leitura na formação dos conceitos físicos estudados, apontando que uma linguagem mais acessível ao conhecimento científico facilitou a transposição didática de conceitos, como descrito por alguns trabalhos, como Flôr e Cassiani (2011), e Kemper; Zimmermann e Gastal (2010).

Todas as respostas analisadas nessas cinco primeiras categorias nos permitem afirmar que esses alunos criaram pseudoconceitos e conceitos potenciais, de acordo com Vygotsky (2008), através da leitura, e que a abstração, como função psíquica superior, deu-se após o devido tratamento didático em sala de aula sobre os elementos físicos de MQ. Isso reforça o uso da interface física-literatura como uma possível ferramenta no ensino de física.

A $6^{\text {a }}$ categoria composta por questões de múltipla escolha de vestibulares e sobre as leituras realizadas, apresentou uma alta taxa de acertos, acima dos 90\%, servindo não só para consolidar os conteúdos ensinados sobre FMC a esses alunos de $3^{\circ} \mathrm{EM}$, como também, para validar a interface física-literatura como ferramenta de ensino de física, pois proporcionou a abstração necessária à apropriação conceitual dos conceitos físicos estudados. Os conceitos abordados nesse grupo de questões (anexo II) exemplifica os conteúdos sobre FMC trabalhados com os alunos ao longo das aulas por meio das leituras e de outros recursos utilizados, como as TIC.

Assim, os conceitos avaliados no anexo II são retratados da seguinte forma: as questões 06, 10, 11 e 12 trataram da dualidade onda partícula. As questões 07, 08, 09, 10, 12, 14 e 17, envolveram tópicos históricos e introdutórios da FMC. Nas questões 09, 10 e 16 trabalhou-se o papel dos experimentos para determinação do caráter ondulatório ou corpuscular da luz e da matéria. A questão 12 abordou a hipótese de Broglie e a natureza dual da matéria. A questão 13 tratou do princípio da incerteza de Heisenberg. A questão 14 buscou abordar a teoria quântica. A questão 16 verificou o colapso da função de onda e papel do observador. E a questão 17, analisou a superposição de estados quânticos. 


\section{Considerações finais}

Considerando que esses alunos não tiveram outro contato com os conteúdos de MQ a não ser pela leitura dos três capítulos de Alice no País do Quantum, da leitura do capítulo XVIII de Hobsbawm, e das TIC, além das aulas com discussões e explicações complementares, podemos considerar que a interface física-literatura é uma ferramenta relevante para o ensino da física. Por meio da leitura, os alunos puderam criar pseudoconceitos, os quais tratados didaticamente pela mediação dada pelo professor foram transformados em conceitos físicos a respeito dos elementos de MQ estudados com esses alunos. Isso é reforçado pelo grande número de acertos nos testes de múltipla escolha, o que nos leva a afirmar que é possível articular essa interface como uma ferramenta didática no ensino da física, desde que o professor assuma seu papel de mediador do ensino e respeite seus alunos como partícipes e protagonistas de seu aprendizado. Esse papel de mediador, aliás, deve ser permanente nesse tipo de abordagem.

A literatura abordada proporcionou aos alunos trabalhar com sua língua natural, permitindo criar uma percepção maior sobre os conceitos físicos por meio das palavras, cujo significado, segundo Vygotsky (2008), é uma generalização, um conceito e um ato restrito ao pensamento, que se transformou em conceitos físicos para esses alunos, além de ter proporcionado um prazer maior ao estudarem a física. Ao dar significado aos conceitos físicos, as palavras deixaram de ser ocas e vazias, passando a constituir uma ponte entre os conceitos potenciais e à abstração necessária para a generalização, que proporcionou a compreensão dos conceitos físicos tratados.

As representações semióticas e a conversão (DUVAL, 1993; 2005), estiveram presentes no estudo realizado. A palavra por meio da leitura se configura como uma representação semiótica que foi utilizada com o intuito de promover a conversão para um pensamento mais abstrato, no caso, os conceitos sobre MQ estudados com os nossos alunos. A transformação de signos matemáticos, da linguagem matemática e da linguagem física, em signos descritos por palavras pertencentes à língua materna dos alunos, além de signos proporcionados pelas analogias, permitiram melhor compreensão e transformação de um sistema semiótico em outro mais abstrato.

Pela análise dos dados pode-se verificar que foi possível promover uma metodologia de ensino por meio da leitura, permitindo emergir os conceitos físicos. A leitura possibilitou que os alunos superassem, significativamente, suas dificuldades na compreensão dos conceitos físicos. A leitura proporcionou o surgimento de pseudoconceitos e conceitos potenciais, como descritos por Vygotsky (2008), que se transformaram em conceitos físicos apropriados sobre MQ, através da interação efetuada entre as diversas formas de aprendizado oferecidas aos alunos. Claro que estamos tomando por base a forma como tais conceitos são apresentados nos materiais didáticos e paradidáticos. A interface física-literatura permitiu observar como os alunos abstraem as palavras e conceitos apresentados em formas analógicas que se transformaram nos conceitos físicos estudados. 
Entendemos que a partir do estudo apresentado, bem como nas confluências presentes nos estudos que tratam das leituras em geral para o ensino de física/ciências, podemos depreender três indicadores para uso da interface física-literatura como uma ferramenta didática ao ensino da física. Esses indicadores podem ser agrupados naquilo que denominamos Indicadores da Interface Física-Literatura, por compreenderem a adaptação entre as duas culturas, física e literatura, cujo resultado final possua características inerentes aos dois sistemas. Nesse sentido, acreditamos que esses indicadores possibilitam uma enculturação do sujeito quanto à compreensão dos conceitos físicos em contextos culturais mais amplos, possibilitando, ao final, uma formação mais abrangente e contextualizada, onde apareçam tanto aspectos conceituais da física, quanto o entendimento destes conceitos como construção humana, relacionando-os com a história, a filosofia e a cultura em geral. Ressaltamos que esses indicadores estão sendo aplicados em novos estudos, como em Lima e Corrallo (2019), a fim de podermos avaliar sua eficácia e, em trabalhos futuros, pretendemos apresentar dados maiores sobre eles.

O primeiro indicador consiste na motivação ou existência de uma base afetivavolitiva e baseia-se nas constatações de Vygotsky (2008) de que o pensamento é gerado pela motivação, onde a vontade é a função psicológica que potencializa as demais funções psíquicas superiores, entre elas a abstração, possibilitando a cognição. A importância desse indicador reside no fato de que é necessário escolher bem a obra literária, ou o texto a ser trabalhado com os alunos, de forma que seja uma leitura agradável e agregadora de sentidos, evitando-se uma leitura que seja mais difícil que a exposição do conceito em si.

O segundo indicador se insere na constatação ou presença de conceitos físicos na literatura, o qual se fundamenta na verificação da existência dos conceitos físicos na leitura que possam ser abstraídos e trabalhados didaticamente pelo professor, possibilitando a didatização conceitual e a formação de sentidos em contextos mais amplos.

$O$ terceiro indicador se refere ao tratamento e conversão dos conceitos presentes na leitura para os conceitos físicos pretendidos. Sua importância se assenta no fato do professor, como mediador do processo ensino-aprendizagem, deve tratar o signo da palavra em língua materna presente na literatura escolhida, e utilizada em sua práxis, convertendo-o para outra linguagem, no caso a conceitual. Para isso pode converter a linguagem simbólica da escrita em linguagem matemática por meio de uma expressão algébrica, ou gráfica, dando sentido àquela e possibilitando a abstração e a compreensão do fenômeno físico em contextos diversos, demonstrando a física como construção humana articulada com a sociedade.

Em nossa percepção, eventuais propostas didáticas que se utilizarem desses indicadores podem propiciar a facilitação do uso da interface física-literatura como uma ferramenta didática ao ensino da física, trazendo sentido e prazer ao estudar física, agregando sentidos aos alunos e proporcionando o entendimento da física articulada com outras formas de conhecimento humano como apresentado neste artigo. Inclusive, um novo trabalho está sendo de- 
senvolvido com o intuito de validar a aplicação destes indicadores em propostas didáticas diversas.

Esperamos que o trabalho apresentado contribua para um ensino de física que priorize mais o estudante que o conteúdo, um ensino mais prazeroso e que ajude o aluno a desenvolver sua abstração, além de propiciar uma aproximação com sua interpretação de mundo. Um ensino que permita seu empoderamento, respeitando-o como protagonista de seu ensino e aprendizagem e que valoriza seu conhecimento e sua forma de se expressar, ao invés de impormos um ensino imutável, que expressa a vontade dos vestibulares a qualquer custo.

Por fim acrescentamos que novas propostas de ensino, sobre outros conteúdos da física, utilizando as relações aqui apresentadas, com aporte dos indicadores da interface físicaliteratura, possam vir a confirmar ou refutar o desenvolvimento da abstração e da apreensão conceitual em jovens estudantes de EM ou ES por meio dessa alternativa didática.

\section{Referências Bibliográficas}

ABDAlLA, M. C. B. O Discreto Charme das Partículas Elementares. São Paulo: Editora Unesp, 2006. 352 p.

ALMEIDA, M. J. P. M.; SILVA, H. C.; MACHADO, J. L. M. Condições de produção no funcionamento da leitura na educação em física. Revista Brasileira de Pesquisa em Educação em Ciências, Belo Horizonte, v. 1, n. 1, p. 5-18, abr. 2001.

ANDRADE, I. B.; MARTINS, I. Discursos de professores de ciências sobre leitura. Revista Investigações em Ensino de Ciências, Porto Alegre, v. 11, n. 2, p. 121-151, ago. 2006.

BACHELARD, G. A Formação do Espírito Científico. Tradução: Estela dos Santos Abreu. Rio de Janeiro: Editora Contraponto, 1996. 316 p.

BARBOSA-LIMA, M. C.; CARVALHO, A. M. P. Linguagem e o ensino de física na escola fundamental. Caderno Brasileiro de Ensino de Física, Florianópolis, v. 20, n.1, p. 86-97, abr. 2003.

BRAGA, E. S. História da Pedagogia. In: Revista Educação - Lev Vigotsky. Publicação Especial (Coleção História da Pedagogia, n. 2). São Paulo: Editora Segmento, 2010. p. 20-29.

BRASIL. Parâmetros curriculares nacionais: Física. Brasília: MEC, 1998. Disponível em: <http://portal.mec.gov.br/seb/arquivos/pdf/ciencian.pdf > Acesso em: 15 mai. 2015.

BROCKINGTON, G. A Realidade Escondida: a dualidade onda-partícula para alunos do Ensino Médio. 2005. 268 f. Dissertação (Mestrado em Ensino de Ciências) - Instituto de Física, USP, São Paulo. 
CARVALHO, S. H. M.; ZANETIC, J. Ciência e arte, razão e imaginação: um projeto de ensino de física moderna para alunos do ensino médio. In: SIMPÓSIO NACIONAL DE ENSINO DE FÍSICA, 16, 2005, Rio de Janeiro. Atas... Rio de Janeiro: SBF, 2005.

CARVALHO, S. H. M.; ZANETIC, J. Ciência e arte, razão e imaginação: complementos necessários à compreensão da física moderna. In: ENCONTRO DE PESQUISA EM ENSINO DE FÍSICA, 9, 2004, Jaboticatubas. Atas... Minas Gerais: SBF, 2004.

CHAVES, T. V.; MEZZOMO, J.; TERRAZAN E. A. Avaliando práticas didáticas de utilização de textos de divulgação científica como recurso didático em aulas de física no ensino médio. In: ENCONTRO NACIONAL DE PESQUISA EM EDUCAÇÃO EM CIÊNCIAS, 3, 2001, Atibaia. Atas... São Paulo: ABRAPEC, 2001.

CHIAPETIA, E. L. A Review of Piagetian Studies Relevant to Science Instruction at the Secondary and College Level. Science Education, v. 2, n. 60, p. 253-261, 1976.

CHRISTIANSON, G. E. Kepler's Somnium: Science Fiction and the Renaissance Scientist. Science Fiction Studies, v. 3, n. 8, p. 1-15, 1976.

CUSTÓDIO PINTO, A. ZANETIC, J. É possível levar a física quântica para o ensino médio? Caderno Catarinense de Ensino de Física, v. 16, n. 1, p. 7-34, abr. 1999.

CUSTÓDIO, J. F.; MODESTO JUNIOR, J. M.. Núcleo central e componentes afetivos das representações sociais de estudantes do ensino médio sobre física. In: SIMPÓSIO NACIONAL DE ENSINO DE FÍSICA, 18, 2009, Vitória. Atas... Espírito Santo: SBF, 2005.

D’Agostin, A.; LEITE, A. E.; HIGA, I.; PAIVA, L. P. Os estudantes do ensino médio e sua relação com a física. In: REUNIÃO ANUAL DA SOCIEDADE BRASILEIRA PARA O PROGRESSO DA CIÊNCIA, 58, 2006, Florianópolis. Atas... Santa Catarina: SBPC, 2006.

DOMINGUINI, L. Física moderna no Ensino Médio: com a palavra os autores dos livros didáticos do PNLEM. Revista Brasileira de Ensino de Física, São Paulo, v. 34, n. 2, p. 1-7, 2012.

DUVAL, R. Registres de représentation sémiotique et fonctionnement cognitif de la pensée. Annales de Didactique et de Sciences Cognitives, Strasbourg: IREM, v. 5, p. 37- 64, 1993.

DUVAL, R. Registros de representações semióticas e o funcionamento cognitivo da compreensão em matemática. In: MACHADO, S. D. A. (Org) Aprendizagem em matemática: registros de representações semióticas. Campinas: Papirus, 2005, p. 11-33.

DUVAL, R. Semiósis e Pensamento Humano: Registros Semióticos e Aprendizagens Intelectuais. São Paulo: Livraria da Física, 2009, 220p. 
FERREIRA, A. A. Ensino de Física das Radiações na Modalidade EJA: Uma Proposta. 2004. 161 f. Dissertação (Mestrado em Ensino de Ciências) - Instituto de Física, USP, São Paulo.

FIEDLER-FERRARA, N. O pensar complexo: construção de um novo paradigma. V!RUS, São Carlos, n. 3, p. 1-20, 2010.

FLÔR, C. C.; CASSIANI, S. O que dizem os estudos da linguagem na educação científica? Revista Brasileira de Pesquisa em Educação em Ciências, Belo Horizonte, v. 11, n. 2, p. 67-86, 2011.

FRANCISCO JUNIOR, W. E. Analogias e situações problematizadoras em aulas de Ciências. São Carlos: Pedro \& João Editores, 2010. 310 p.

FRANCISCO JUNIOR, W. E. Aprendendo sobre o funcionamento da ciência a partir da leitura em sala de aula. In: ENCONTRO NACIONAL DE PESQUISA EM EDUCAÇÃO EM CIÊNCIAS, 7, 2009. Florianópolis. Anais... Santa Catarina: ABRAPEC, 2009.

FREIRE, P. Pedagogia do oprimido. Rio de Janeiro: Paz e Terra, 1975. 256 p.

GASPAR, A. Cinquenta anos de ensino de física: muitos equívocos, alguns acertos e a necessidade de recolocar o professor no centro do processo educacional. Educação: Revista de Estudos da Educação, Maceió, v. 13, n. 21, p. 71-91, dez. 2004.

GILMORE, R.. Alice no País do Quantum. Rio de Janeiro: Editora Jorge Zahar, 1998. 196 p.

GONÇALVES JÚNIOR W. P.; BARROSO M. F. As questões de física e o desempenho dos estudantes no ENEM. Revista Brasileira de Ensino de Física, São Paulo, v.36, n. 1, p. 1-16, 2014.

GRECA, I. M.; MOREIRA, M. A.; HERSCOVITZ, V. E. Uma proposta para o ensino de Mecânica Quântica. Revista Brasileira de Ensino de Física, São Paulo, v. 23, n. 4, p. 444$457,2001$.

GUERRA, A.; MENEZES, A. M. S.. Literatura na Física: Uma Possível Abordagem para o Ensino de Ciências? In: ENCONTRO NACIONAL DE PESQUISA EM EDUCAÇÃO EM CIÊNCIAS, 7, 2009. Florianópolis. Anais... Santa Catarina: ABRAPEC, 2009.

GURGEL, I. PIETROCOLA, M. O papel da imaginação no pensamento científico: análise da criação científica de estudantes em uma atividade didática sobre o espalhamento de Rutherford. Caderno Brasileiro de Ensino de Física. Florianópolis, v. 28, n. 1, p. 91-122, abr. 2011a. 
GURGEL, I; PIETROCOLA, M. Uma discussão epistemológica sobre a imaginação científica: a construção do conhecimento através da visão de Albert Einstein. Revista Brasileira de Ensino de Física, São Paulo, v. 33, n. 1, p. 1-12, 2011 b.

HOBSBAWM, E. Era dos extremos: o breve século XX: 1914-1991. São Paulo: Companhia das Letras, 1995. 632 p.

JOURNAL OF RESEARCH IN SCIENCE TEACHING. The Reading Science Learning Writing Connection, John Wiley 7 Sons, Inc. v. 31, n. 9, p. 877-893, 1994.

KEMPER, A.; ZIMMERMANN, E.; GASTAL, M. L. Textos populares de divulgação científica como ferramenta didático-pedagógica: o caso da evolução biológica. Revista Brasileira de Pesquisa em Educação em Ciências, Belo Horizonte, v. 10, n. 3, p. 25-50, 2010.

KHLYABICH, I. Pequena história da filosofia. São Paulo: Editora e distribuidora de livros Ltda., 1967. 210 p.

KINOUCHI, O; KINOUCHI J. M.; MANDRÁ, A. A. Metáforas científicas no discurso jornalístico. Revista Brasileira de Ensino de Física, São Paulo, v. 34, n. 4, p. 1-12, 2012.

KRASILCHIK, M.. Reformas e realidade: o caso do ensino das ciências. São Paulo Perspec., São Paulo, v. 14, n. 1, p. 85-93, mar. 2000.

KUHN T. A tensão essencial. Lisboa: Edições 70, 1977. 408 p.

LAKOFF, G.; JOHNSON, M. Metaphors We Live By. Chicago: University of Chicago Press, 1980. 242 p.

LAKOFF, G.; NÚÑEZ, R. Where Mathematics Comes From. New York: Basic Books, 2000. 489 p.

LIMA, L. G. A abstração como ponte entre a física e a literatura na construção de conceitos de mecânica quântica no ensino médio. 2014. 353 f. Dissertação (Mestrado em Ensino de Física) - Instituto de Física da Universidade de São Paulo, São Paulo.

LIMA, L. G. O estudo do Movimento Retilíneo Uniforme dos corpos através da leitura de trechos da $2^{\mathrm{a}}$ Jornada do livro Diálogo Sobre os Dois Máximos Sistemas do Mundo Ptolomaico e Copernicano, de Galileu Galilei. Física na Escola, v. 13, n. 1, p. 24-29, 2012.

LIMA, L. G.; CORRALlO, M. V. Trinta anos de física também é cultura: apresentação de estratégias didáticas para o ensino da interface física-literatura por meio de indicadores. In: SIMPÓSIO NACIONAL DE ENSINO DE FÍSICA, 23, 2019, Salvador. Atas... Bahia: SBF, 2019.

LIMA, L. G.; RICARDO, E. C.. Física e Literatura: uma revisão bibliográfica. Caderno Brasileiro de Ensino de Física, Florianópolis, v. 32, n. 3, p. 577-617, 2015. 
MACHI, F.; LEITE, C. A leitura no ensino de física no cenário dos periódicos nacionais. In: ENCONTRO NACIONAL DE PESQUISA EM ENSINO DE FÍSICA, 12, 2010. Águas de Lindóia. Anais... São Paulo: SBF, 2010.

MARICONDA, P. R. Diálogo sobre os dois máximos sistemas do mundo Ptolomaico e Copernicano. São Paulo: Imprensa Oficial, 2004. 888 p.

MECKE, K. R. A Imagem da Literatura na Física. Gazeta de Física, v. 27, n. 4, p. 4-13, nov. 2004.

MELHORATO, R. L.; NICOLI, G. T. Da física clássica a moderna: o simples toque de uma sirene. Revista Brasileira de Ensino de Física, v. 34, n. 3, p. 1-4, 2012.

MENEZES, L.C., KAWAMURA, R.D.; HOSOUME, Y. Objetos e objetivos no aprendizado da Física. In: ENCONTRO DE PESQUISA EM ENSINO DE FÍSICA, 4, 1994. Florianópolis. Anais... Santa Catarina: SBF, 1994.

MENEZES, L. C. Uma Física para o Novo Ensino Médio. Física na Escola, v. 1, n.1, p. 6-8, out. 2000 .

MONTEIRO, I. C. C.; GASPAR, A.; MONTEIRO, M. A. A. A motivação dos alunos num contexto de leitura de texto de divulgação científica. In: SIMPÓSIO NACIONAL DE ENSINO DE FÍSICA, 16, 2005, Rio de Janeiro. Atas... Rio de Janeiro: SBF, 2005

NASCIMENTO, C.; BARBOSA-LIMA, M. C. O ensino de física nas séries iniciais do ensino fundamental: Lendo e escrevendo histórias. Revista Brasileira de Pesquisa em Educação em Ciências, v. 6, n. 3, p. 1-11, 2006.

NASCIMENTO, T. G.; REZENDE JUNIOR, M. F. A produção sobre divulgação científica na área de educação em ciências: Referenciais teóricos e principais temáticas. Revista Investigações em Ensino de Ciências, v. 15, n. 1, p. 97-120, 2010.

NIGRO, R. G.; TRIVELATO, S. L. F. Leitura de textos de ciências de diferentes gêneros: um olhar cognitivo-processual. Revista Investigações em Ensino de Ciências, v. 15, n. 3, p. 553-573, 2010.

NORY, R. M.; ZANETIC, J. O teatro e a física: a cena que não entra em sala. In: SIMPÓSIO NACIONAL DE ENSINO DE FÍSICA, 16, 2005, Rio de Janeiro. Atas... Rio de Janeiro: SBF, 2005.

OCDE. Organização para Cooperação e Desenvolvimento Econômico. Programme for International Student Assessment. Reading, mathematical and scientific literacy. Paris, 2000 . 
OSTERMANN, F.; MOREIRA, M. A. Uma revisão bibliográfica sobre a área de pesquisa "Física Moderna e Contemporânea no Ensino Médio". Revista Investigações em Ensino de Ciências, v. 5, n. 1, p. 23-48, 2000.

PADILHA, J. N.; CARVALHO, A. M. P. Relações entre os gestos e as palavras utilizadas durante a argumentação dos alunos em uma aula de conhecimento físico. Revista Brasileira de Pesquisa em Educação em Ciências, v. 11, n. 2, p. 1-16, 2011.

PAULA, H. F.; BORGENS, A. T. A compreensão dos estudantes sobre o papel da imaginação na produção das ciências. Caderno Brasileiro de Ensino de Física, v. 25, n. 3, p. 478506, dez. 2008.

PAULA, H. F.; LIMA, M. E. C. C. L. Formulação de questões e mediação da leitura. Revista Investigações em Ensino de Ciências, v. 15, n. 3, p. 429-461, 2010.

PEREIRA, J. M.; LONDERO, L. O ensino de partículas elementares por meio da leitura de "Alice no País do Quantum". In: SIMPÓSIO NACIONAL DE ENSINO DE FÍSICA, 20, 2013, São Paulo. Atas... São Paulo: SBF, 2013.

PESSOA JÚNIOR, O. Conceitos de Física Quântica. São Paulo: Livraria da Física, 2003. $188 \mathrm{p}$.

PIETROCOLA, M.; SIQUEIRA, M. A Transposição Didática aplicada a Teoria Contemporânea: A Física de Partículas no Ensino Médio. In: ENCONTRO NACIONAL DE PESQUISA EM ENSINO DE FÍSICA, 10, 2006. Londrina. Anais... Paraná: SBF, 2006.

REZENDE, F.; OSTERMANN F.; FERRAZ, G. Ensino-aprendizagem de física no nível médio: o estado da arte da produção acadêmica no século XXI. Revista Brasileira de Ensino de Física, v. 31, n. 1, p. 1-8, 2009.

RICARDO, E. C.; FREIRE, J. C. A. A concepção dos alunos sobre a física do ensino médio: um estudo exploratório. Revista Brasileira de Ensino de Física, v. 29, n. 2, p. 251-266, 2007.

ROBILOTTA, M. R. O Cinza, o Branco e o Preto - da relevância da História da Ciência no ensino da Física. Caderno Catarinense do Ensino de Física, v.5 (número especial), p. 0722, jun. 1988.

SBF. Sociedade Brasileira de Física. Artigos da RBEF discutem presente e futuro do ensino da física. São Paulo: SBF, 2014.

SNOW, C. P. As duas culturas e uma segunda leitura: Uma versão ampliada das duas culturas e a revolução científica. São Paulo: Editora da Universidade de São Paulo, 1995. $136 \mathrm{p}$. 
SOUZA, R. R.; SOUZA, P. H. Textos com erros conceituais e o ensino de física.. In: ENCONTRO NACIONAL DE PESQUISA EM EDUCAÇÃO EM CIÊNCIAS, 5, 2005. Bauru. Anais... São Paulo: ABRAPEC, 2005.

STRACK, R.; LOGUÉRCIO, R.; DEL PINO, J. C. Percepções de professores de ensino superior sobre a literatura de divulgação científica. Ciência \& Educação, v. 15, n. 2, p. 425-42, 2009.

TEIXEIRA, F. M.; MENDES, I. A.; Na mesa com Alice: sobre diálogos matemáticos a partir da obra de Lewis Carroll. In: ENCONTRO LATINO AMERICANO DE INICIAÇÃO CIENTÍFICA E VI ENCONTRO LATINO AMERICANO DE PÓS-GRADUAÇÃO, 10, 2006. São José dos Campos. Anais... São Paulo, 2006.

TERRAZZAN, E. A. A inserção da Física Moderna e Contemporânea no Ensino de Física na escola de $2^{\circ}$ grau. Caderno Catarinense de Ensino de Física, Florianópolis, v. 9, n. 3, p. 209-214, dez. 1992.

VIENNOT, L. 'Le raisonnement spontané en dynamique élémentaire. 1977, 224 f. Tese de doutorado - Universidade Paris VII, Paris.

VYGOTSKY, L. S. Obras Escogidas Tomo II. Madrid: Visor Distribuiciones. 1994, 512 p.

VYGOTSKY, L. S. Pensamento e Linguagem. São Paulo: Editora Martins Fontes, 2008. $212 \mathrm{p}$.

WATANABE, G.; GURGEL, I. A imaginação como processo de criação na arte e na física: uma discussão sobre a dualidade no entendimento. In: SIMPÓSIO NACIONAL DE ENSINO DE FÍSICA, 19, 2011. Manaus. Anais... Amazonas: SBF, 2011.

ZAMBON, L. B.; TERRAZZAN, E. A. Analogias produzidas por alunos do ensino médio em aulas de física. Revista Brasileira de Ensino de Física, v. 35, n. 1, p. 1-9, 2013.

ZANETIC, J. Física e Arte: uma ponte entre duas culturas. Pro-Posições, v. 17, n. 1, p. 39-58, 2006a.

ZANETIC, J. Física e literatura: construindo uma ponte entre as duas culturas. Hist. cienc. Saúde-Manguinhos, v.13, n. (suplemento), p. 55-70, $2006 \mathrm{~b}$.

ZANETIC, J. Física e literatura: uma possível integração no ensino. In: ENCONTRO DE PESQUISA EM ENSINO DE FÍSICA, 5, 1996. Águas de Lindóia. Anais... São Paulo: SBF, 1996. 
01 - A leitura introdutória do capítulo XVIII - Feiticeiros e Aprendizes, da Era dos Extremos, de Hobsbawm, foi pertinente para compreensão inicial, e entendimento da importância dos estudos sobre a Física Moderna?

02 - Após sua leitura sobre a alegoria de Alice no País do Quantum, é valido considerar ser possível mesclar a física com a literatura, melhorando seu aprendizado sobre os conceitos físicos estudados? Comente.

03 - Você considera o uso de leituras, textos literários, narrativas e figuras de linguagem, além de outros recursos linguísticos, proveitosos para o ensino da física? Explique.

No livro verificamos que o autor usou a imaginação para criar os personagens e o enredo da história, inserindo os conceitos sobre física quântica por intermédio de figuras de linguagem, analogias e modelos representativos da quântica. A esse respeito, responda os itens 04 a 06.

04 - Você considera a imaginação importante para a literatura e escrita de histórias? E para a física, a imaginação é importante? Explique.

05 - Por meio da literatura é possível mostrar que a ciência, também, tem características imaginativa e abstrata?

06 - A imaginação poética ou literária pode ser entendida na mesma importância da imaginação científica?

07 - Você considerou bom o uso da literatura nos estudos físicos? De que forma esse uso aproximou os conceitos físicos de você?

08 - Na leitura do livro Alice no País do Quantum, podemos interpretar que as alegorias, as analogias usadas pelo autor, ou seja, a criação dos personagens e do enredo da história, mesclando os conceitos de física quântica, podem ser consideradas como modelos? Explique.

09 - As leituras realizadas ajudaram a você criar, pelo menos uma vaga ideia (generalizações e pseudoconceitos), sobre os conceitos científicos estudados em sala? Explique usando algum exemplo.

10 - Os vídeos ajudaram a formação de seu entendimento sobre os conceitos científicos estudados? O que você julga mais importante para seu aprendizado: o vídeo que já traz uma interpretação própria e pronta ao telespectador? Ou a leitura que lhe garante abstrair os eventos ali escritos? 


\section{Anexo II: Questionário sobre conteúdos de Física Moderna e Contemporânea}

01 - Antes mesmo de ter uma ideia mais correta do que é a luz, o homem percebeu que ela era capaz de percorrer muito depressa enormes distâncias. Tão depressa que levou Aristóteles - famoso pensador grego que viveu no século IV a.C. e cujas obras influenciaram todo o mundo ocidental até a Renascença - a admitir que a velocidade da luz seria infinita.

(GUIMARÃES, L. A.; BOA, M. F. "Termologia e óptica". São Paulo: Harbra, 1997. p. 177).

Hoje se sabe que a luz tem velocidade de aproximadamente $300.000 \mathrm{~km} / \mathrm{s}$, que é uma velocidade muito grande, porém finita. A teoria moderna que admite a velocidade da luz constante em qualquer referencial e, portanto, torna elásticas as dimensões do espaço e do tempo é:

a) a teoria da relatividade

b) a teoria da dualidade onda - partícula

c) a teoria atômica de Bohr

d) o princípio de Heisenberg

e) a lei da entropia.

02 - Entre outras consequências, a teoria da relatividade de Einstein, poria fim à ideia do éter, meio material necessário, semelhantemente ao som, através do qual a luz se propagava. O jargão popular "tudo é relativo" certamente não se deve a ele, pois seus postulados estão fundamentados em algo absoluto: a velocidade da luz no vácuo $-300.000 \mathrm{~km} / \mathrm{s}$.

Hoje sabe-se que:

I. O som propaga-se no vácuo.

II. A luz propaga-se no vácuo.

III. A velocidade da luz no vácuo é a velocidade limite do universo.

É (são) verdadeira(s):

a) todas b) nenhuma c) somente II d) II e III e) somente III

03 - Com o advento da Teoria da Relatividade de Einstein, alguns conceitos básicos da física newtoniana, entre eles, o espaço e o tempo, tiveram de ser revistos. Qual a diferença substancial desses conceitos para as duas teorias?

\begin{tabular}{|l|c|c|c|c|}
\hline \multirow{2}{*}{ Alternativas } & \multicolumn{2}{|c|}{ Física newtoniana } & \multicolumn{2}{c|}{ Teoria da relatividade } \\
\cline { 2 - 5 } & espaço & tempo & espaço & tempo \\
\hline a) & Absoluto & Absoluto & Dilata & Contrai \\
\hline b) & Dilata & Absoluto & Contrai & Dilata \\
\hline c) & Absoluto & Contrai & Dilata & Absoluto \\
\hline d) & Absoluto & Absoluto & Contrai & Dilata \\
\hline e) & Contrai & Dilata & Absoluto & absoluto \\
\hline
\end{tabular}


04 - A noção de que o tempo se acelera ou desacelera dependendo da velocidade com que um objeto se desloca relativamente a outro certamente está entre as ideias mais ousadas de Albert Einstein. O termo "dilatação do tempo" foi cunhado para descrever a desaceleração do tempo provocada pelo movimento. Para ilustrar o efeito, Einstein propôs um exemplo, conhecido por paradoxo dos gêmeos. Nesse suposto paradoxo, um dos gêmeos viaja quase com a velocidade da luz para uma estrela distante e volta à Terra.

De acordo com a teoria da relatividade, quando voltar para Terra esse gêmeo:

a) apresentará a mesma idade de seu irmão, pois são gêmeos.

b) aparentará estar mais velho devido ao desgaste de uma viagem tão longa.

c) estará mais jovem que seu irmão que ficou na Terra, pois o tempo se dilatou.

d) estará mais velho que seu irmão que ficou na Terra, pois o tempo se dilatou.

e) nenhuma das anteriores.

05 - O quadro de Salvador Dali "A persistência da memória" representada abaixo data de 1934. Esta pintura traduz o interesse do pintor pelas conquistas da ciência moderna, cruzando teorias mais abstratas da física, nomeadamente que colocou em causa a ideia de espaço e tempo fixos, com as pesquisas de Freud relativamente ao inconsciente e à importância dos fenômenos dos sonhos. Na tela encontram-se representados três relógios que marcam diferentes horas tendo como fundo a paisagem de Porto Lligat, localizado no norte de Espanha. A duplicidade de sentido das imagens e as inúmeras interpretações que promovem assim como a tendência para a criação de cenas absurdas repletas de signos indecifráveis levaram a Dali a designar esta forma de arte de crítica paranoica, em tudo oposta a uma visão racional do mundo.

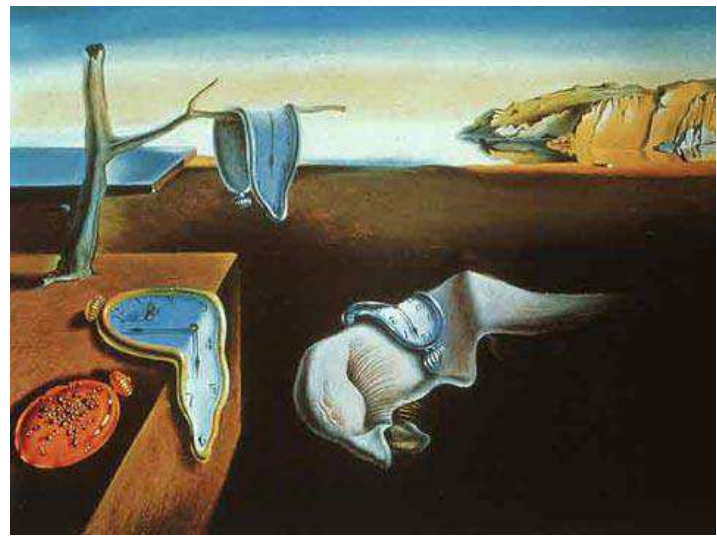

A teoria que completa a lacuna trata-se da (o):

a) Relatividade de Einstein

b) colapso do ultravioleta

c) corpo negro

d) superposição

e) big-bang

06 - Assinale a alternativa que preenche corretamente as lacunas do texto abaixo:

Segundo a interpretação vigente, a radiação eletromagnética tem uma natureza bastante complexa. Em fenômenos como interferência e difração, por exemplo, ela apresenta um comportamento.

Em processos de emissão e absorção, por outro lado, ela pode apresentar comportamento. sendo, nesses casos, descrita por "pacotes de energia" (fótons) que se movem no vácuo com velocidade $\mathrm{c} \approx 300.000 \mathrm{~km} / \mathrm{s}$ e têm massa de repouso.

a) ondulatório - ondulatório - nula

b) ondulatório - corpuscular - nula

c) corpuscular - ondulatório - diferente de zero

d) corpuscular - corpuscular - nula

e) ondulatório - corpuscular - diferente de zero 
07 - Com base nos tópicos de Física Moderna estudados, assinale a(s) proposição(ões) CORRE$\mathbf{T A}(\mathbf{S})$ e assinale a alternativa que contem a sua soma.

01. Corpo negro ideal é todo corpo capaz de absorver toda a radiação que nele incide. Quando um corpo negro é aquecido, ele é uma fonte ideal de radiação térmica.

02. O efeito fotoelétrico só ocorre se a intensidade da luz incidente sobre o metal for alta e a emissão de cargas elétricas deste material independe da frequência da radiação incidente.

04. A Teoria da Relatividade Especial, proposta por Einstein, está baseada em dois postulados, sendo que um deles é enunciado da seguinte forma: "As leis da Física são as mesmas em todos os referenciais inerciais. Ou seja, não existe nenhum sistema de referência inercial preferencial".

08. A apresentação do trabalho do físico Maxwell sobre a quantização da energia é considerada hoje como o marco oficial da fundação da Física Moderna.

16. A Teoria da Relatividade Restrita tem como consequência a contração espacial e a dilatação temporal.

32. O fenômeno da radiação do corpo negro é explicado pela Física Clássica e pela Moderna como sendo uma distribuição contínua de energia de um sistema.

64. O comportamento dualístico de uma onda-partícula é descrito e aceito pela Física Clássica, sendo mais aprofundado e explicado pela Física Quântica.
a) 15
b) 14
c) 24
d) 48
e) 21

08 - Em fins do século XIX, William Thomson, conhecido mais por Lorde Kelvin, um dos mais destacados e respeitados físicos da época, fazendo uma avaliação da situação da Física, afirmou que todos os problemas já haviam sido resolvidos: "No céu azul da física existem apenas duas nuvens a serem dirimidas". O que Lorde Kelvin não sabia, era que essas duas nuvens se transformariam em tempestades, formando uma nova física, denominada atualmente como física quântica.

As duas nuvens a que Kelvin se referira eram dois problemas sem solução para época, assinale a alternativa que os contenham.

a) a geração de $100 \%$ de energia em uma máquina térmica e a difração da luz;

b) a questão do éter e do corpo negro;

c) o problema da radiação eletromagnética e a queda dos corpos;

d) o ângulo de curvatura horizontal e vertical para alcances máximos;

e) a construção de máquinas mais potentes e do aquecimento global.

09 - A natureza da luz já foi discutida por séculos entre os cientistas. Newton a considerava uma partícula, enquanto Huygens, seu contemporâneo, postulava-a como uma onda. Os primeiros experimentos capazes de determinar a característica ondulatória e corpuscular (feita de partículas) da luz foram realizados, também, em séculos diferentes, o primeiro em 1801, por Thomas Young, e o segundo em 1905 por Albert Einstein.

Os experimentos citados são denominados como:

a) medida de uma altura pela sombra projetada e radiação do corpo negro;

b) decomposição da luz solar em um prisma e radiação do corpo negro;

c) comprovação da inexistência do éter e espalhamento beta;

d) paradoxo da incerteza e relatividade geral;

e) dupla fenda e efeito fotoelétrico.

10 - Entre as inovações da Física que surgiram no início do século XX, uma foi o estabelecimento da teoria , que procurou explicar o surpreendente resultado apresentado pela radiação e pela matéria conhecido como dualidade entre e ondas. Assim, quando se faz um feixe de elétrons passar por uma dupla fenda de largura micrométrica, o efeito observado é o comportamento 
da matéria, e quando fazemos um feixe de luz incidir sobre uma placa metálica, o efeito observado pode ser explicado considerando a luz como um feixe de

Assinale a alternativa que apresenta a sequência correta de palavras para o preenchimento das lacunas nas frases acima.

a) Relativística - partículas - ondulatório - partículas.

b) Atomística - radiação - rígido - ondas.

c) Quântica - partículas - ondulatório - partículas.

d) Relativística - radiação - caótico - ondas.

e) Quântica - partículas - ondulatório - ondas.

11 - Leia a Tirinha a seguir:
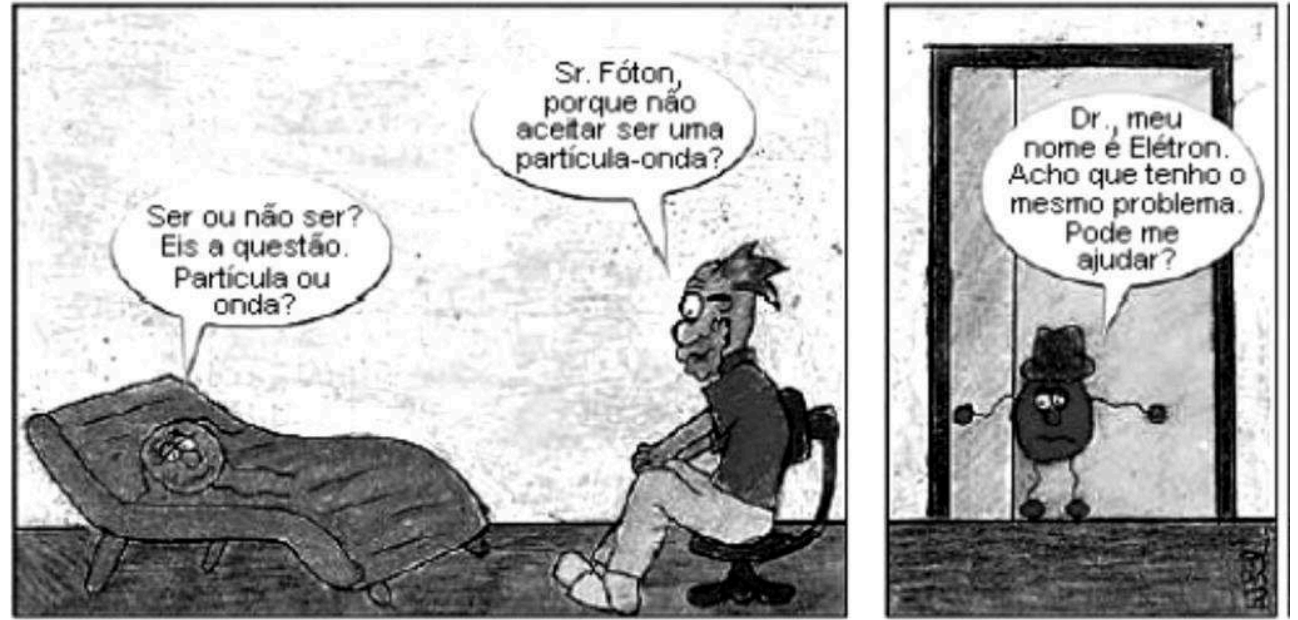

Disponivel em: ahttp:/Awww.cbpt brireduhqhtml/tirinhasis. Acesso em: 25 ago. 2008.

Para validar a proposta do analista, ocorrência da dualidade onda-partícula, o senhor Fóton deve ser capaz de sofrer:

a) interferência e refração.

c) difração e efeito fotoelétrico.

b) interferência e polarização.

e) polarização e ressonância.

d) efeitos fotoelétrico e compton.

12 - Em 1926, Louis de Broglie formula, na sua tese de doutorado, que as partículas deveriam se comportar como ondas. A hipótese de Broglie foi confirmada experimentalmente de forma independente por Davisson e Germer, em experiências realizadas usando elétrons onde a difração de partículas foi observada pela primeira vez. Nestes experimentos, as partículas incidem em uma rede de difração, que consiste de uma série de fendas do mesmo comprimento localizadas a uma distância igualmente espaçada, conhecida como espaçamento da rede. O comprimento da fenda deve ser comparável com o comprimento da onda incidente.

Em sua teoria De Broglie considerou, pelo princípio da simetria da natureza, que a matéria apresentava:
a) características luminosas
b) caráter dual
c) aspectos sonoros
d) efeito doppler
e) características rígidas.

13 - O célebre historiador Hobsbawm, em seu livro A Era dos Extremos, no capítulo XVIII - Feiticeiros e aprendizes, ressalta que o aprendiz de feiticeiro não mais precisa do seu mestre. Alertandonos, com a analogia, que o ser humano do século 20 não precisava conhecer a ciência por trás da tecnologia que usava, pois ela já vinha pronta, bastando saber apertar alguns botões. Além dessa 
contradição, o autor aponta, também, o conflito pelo qual os cientistas passaram com o desaparecimento das certezas da física clássica, tais como a determinação da posição e velocidade das partículas, como os elétrons, para os quais não havia mais posição e velocidades bem determinadas. A teoria que evidencia essa passagem está bem explicada pelo(a):
a) o principio de incerteza de Heisenberg
b) o princípio de exclusão de Pauli
c) o paradoxo do gato de Schrödinger
d) a quantização de Planck

e) a relatividade de Einstein

14 - Niels Bohr, ao se deparar com as estranhezas da física quântica, mais detalhadamente sobre a mecânica quântica, teria dito que: "qualquer um que não se choque com a Mecânica Quântica é porque não a entendeu". Na mesma linha de pensamento Werner Heisenberg dizia: "o quantum é essencialmente a ciência além do sentido. Não é possível ter qualquer imagem da realidade final".

As duas frases podem ser explicadas no assombro que a mecânica quântica causa aos nossos sentidos, por ser tão diferente da nossa percepção. Assinale abaixo o que poderia sintetizar esse assombro:

a) a inexistência comprovada do éter

b) os elétrons arrancados de uma placa de metal pelo efeito fotoelétrico

c) a radiação do corpo negro323

d) a superposição de estados quânticos de uma partícula, que impede uma verificação possível de sua localização.

e) O princípio de exclusão de Pauling que afirma ser impossível dois férmions ocuparem o mesmo estado quântico.

15 - A teoria quântica descreve o comportamento de partículas em termos de distribuições de probabilidade, e a observação real de partículas individuais ocorre aleatoriamente dentro destas distribuições. A figura ilustra a teoria.

Assinale a alternativa que melhor explica a distribuição de probabilidades.

a) é um arremesso a esmo de probabilidades da realidade, denominado chute.

b) representa a sorte, como no jogo de dados que pode dar

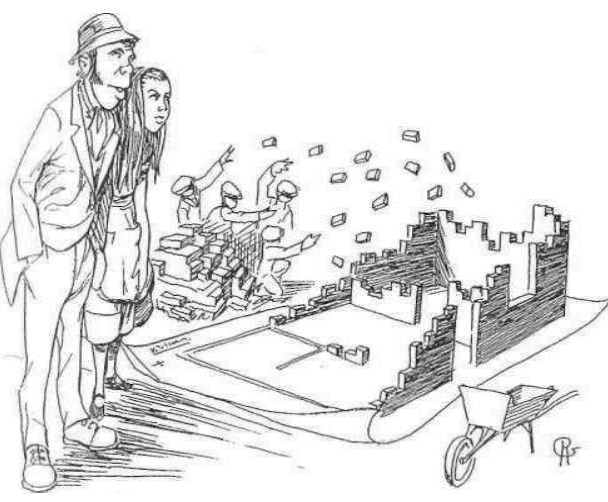
seis ou um.

c) constitui uma possível determinação da posição de um elétron, dada em possibilidades de verificação aleatórias dentro das distribuições.

d) nos traduz a exata posição do elétron e sua velocidade.

e) indica somente a probabilidade do observador de verificar onde se encontra uma partícula.

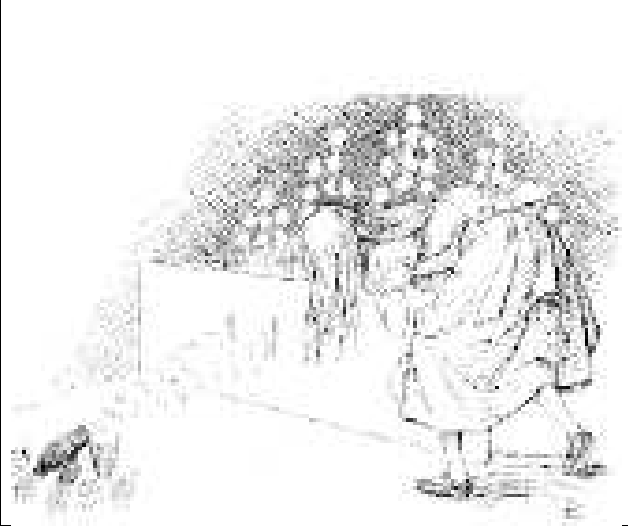

16 - A quântica trata dos eventos ocorridos em escalas atômicas, nesse mundo, nossos sentidos não retratam a realidade dos fatos. Um exemplo é o que ocorre com o papel do observador em um experimento, pois quando se tenta realizar a observação o experimento muda.

A figura ilustra o fenômeno da difração, os elétrons atravessam uma dupla fenda, criando padrões de interferência (fenômeno ondulatório da difração), a personagem ao ten- 
tar observar por qual das fendas os elétrons passam, acaba interferindo e o que se constata no anteparo atrás das fendas será:

\section{ALÍCE NO PAÍS DO QUANTUM, p.51}

a) o colapso da função de onda, o padrão de interferência desaparece e atrás das fendas surgem apenas duas riscas verticais, que indicam o caráter corpuscular dos elétrons.

b) a continuidade do padrão de interferência (franjas), mantendo-se a difração dos elétrons, que indicam o caráter ondulatório dos elétrons.

c) o desaparecimento da difração e o surgimento da polarização;

d) a continuidade das franjas de interferência que representam o caráter corpuscular dos elétrons.

e) o desaparecimento dos pontos claros (franjas) e apenas a verificação de interferências destrutivas.

Leia o texto para responder a próxima questão

Irwin Schrödinger desenvolveu um experimento gedanken (experimento de pensamento) em que um pobre gato ficava preso numa caixa, junto com um recipiente de gás venenoso e um mecanismo que quebraria o frasco caso uma amostra de um material radioativo viesse sofrer um decaimento. Tal decaimento é definitivamente um processo quântico. O material pode ou não decair e então, de acordo com as regras da física quântica, haveria uma superposição de estados, onde em alguns o decaimento teria ocorrido e em outros, não. É claro que, naqueles estados em que o decaimento ocorresse, o gato morreria, e nós então teríamos uma superposição de estados de gato, alguns mortos e alguns vivos. Quando a caixa fosse aberta, alguém observaria o gato e dali em diante ele estaria morto ou vivo. A questão proposta por Schrödinger era: "Qual o estado do gato antes de a caixa ser aberta"? (Alice no País do Quantum, p. 54).

17 - Assinale a alternativa que representa a correta explicação sobre superposição de estados quânticos.

a) representa o estado das pessoas com doenças terminais, estando meio vivas ou mortas.

b) indica tão somente a possibilidade de uma partícula estar em dois ou mais estados quânticos ao mesmo tempo.

c) é uma verificação da realidade observada no nosso dia a dia.

d) a superposição é a prova da dualidade da luz.

e) é a capacidade do elétron apresentar o fenômeno da difração.

\section{GABARITO}

$\begin{array}{llllll}01-\mathrm{A} & 02-\mathrm{D} & 03-\mathrm{D} & 04-\mathrm{C} & 05-\mathrm{A} & 06-\mathrm{B} \\ 07-\mathrm{E} & 08-\mathrm{B} & 09-\mathrm{E} & 10-\mathrm{C} & 11-\mathrm{C} & 12-\mathrm{B} \\ 13-\mathrm{A} & 14-\mathrm{D} & 15-\mathrm{C} & 16-\mathrm{A} & 17-\mathrm{B} & \end{array}$

